\title{
Combined Calorimetry, Thermo-Mechanical Analysis and Tensile Test on Welded EN AW-6082 Joints
}

\author{
Philipp Wiechmann ${ }^{1}$, Hannes Panwitt ${ }^{2}$, Horst Heyer ${ }^{2}$, Michael Reich ${ }^{1, *}$, Manuela Sander ${ }^{2}$ and \\ Olaf Kessler 1,3 \\ 1 Institute of Materials Science, Faculty of Mechanical Engineering and Marine Technology, \\ University of Rostock, Albert Einstein-Str. 2, 18059 Rostock, Germany; \\ philipp.wiechmann@uni-rostock.de (P.W.); olaf.kessler@uni-rostock.de (O.K.) \\ 2 Institute of Structural Mechanics, Faculty of Mechanical Engineering and Marine Technology, \\ University of Rostock, Albert Einstein-Str. 2, 18059 Rostock, Germany; \\ hannes.panwitt2@uni-rostock.de (H.P.); horst.heyer@uni-rostock.de (H.H.); \\ manuela.sander@uni-rostock.de (M.S.) \\ 3 Competence Centre CALOR, Department Life, Light \& Matter, Faculty of Interdisciplinary Research, \\ University of Rostock, Albert-Einstein-Str. 25, 18059 Rostock, Germany \\ * Correspondence: michael.reich@uni-rostock.de; Tel.: +49-381-498-9490
}

Received: 11 July 2018; Accepted: 7 August 2018; Published: 9 August 2018

\begin{abstract}
Wide softening zones are typical for welded joints of age hardened aluminium alloys. In this study, the microstructure evolution and distribution of mechanical properties resulting from welding processes of the aluminium alloy EN AW-6082 (AlSi1MgMn) was analysed by both in-situ and ex-situ investigations. The in-situ thermal analyses included differential scanning calorimetry (DSC), which was used to characterise the dissolution and precipitation behaviour in the heat affected zone (HAZ) of welded joints. Thermo-mechanical analysis (TMA) by means of compression tests was used to determine the mechanical properties of various states of the microstructure after the welding heat input. The necessary temperature-time courses in the HAZ for these methods were measured using thermocouples during welding. Additionally, ex-situ tensile tests were done both on specimens from the fusion zone and on welded joints, and their in-depth analysis with digital image correlation (DIC) accompanied by finite element simulations serve for the description of flow curves in different areas of the weld. The combination of these methods and the discussion of their results make an essential contribution to understand the influence of welding heat on the material properties, particularly on the softening behaviour. Furthermore, the distributed strength characteristic of the welded connections is required for an applicable estimation of the load-bearing capacity of welded aluminium structures by numerical methods.
\end{abstract}

Keywords: AlMgSi alloy; EN AW-6082; welding; mechanical properties; microstructure; DSC; thermo-mechanical analysis; digital image correlation; tensile test; numerical simulation

\section{Introduction}

Wrought EN AW-6082 (AlSi1MgMn) alloy, as an age hardening aluminium alloy, has excellent weldability, corrosion resistance and mechanical strength and is widely used in the automobile and shipbuilding industries. The major alloying elements of this aluminium alloy $6082 \mathrm{are} \mathrm{Mg}$ and $\mathrm{Si}$, which can increase the strength of the alloy through precipitation hardening. The welding of aluminium alloys can lead to defects such as porosity, incomplete fusion and hot cracking, and thus the welding work can be challenging. Age hardening aluminium alloys such as 6082, whose strength is increased by precipitation hardening, always exhibit phase transformation and a softening phenomenon because of the heat input generated during the welding process [1,2]. A proven method for investigations of 
such softening is the characterisation of microstructure and mechanical properties of welded joints by metallography as well as by standard load tests. Results (e.g., [3]) show the decreases of base material strength within the heat affected zone due to the dissolution of strengthening precipitates. For deeper knowledge and understanding of the softening phenomena, an in-situ characterisation of the microstructure development would be preferable. Differential scanning calorimetry is a suitable technique to record the precipitation and dissolution behaviour in situ during the heat treatment of aluminium alloys [4]. The method was initially developed for analysis of the precipitation behaviour during cooling after solution annealing and was subsequently expanded to the analysis of the short-term heat treatment of age-hardening aluminium alloys [5,6]. For a correct understanding of softening phenomena within the HAZ, knowledge of phase transformations during heating would be necessary. In this work, DSC was used for the first time to investigate the dissolution and precipitation behaviour of an age-hardened AlMgSi alloy when heated under typical temperature-time curves of a welding process. The results of the thermal analysis are discussed alongside the distributed mechanical properties of the HAZ, which have been determined in two ways. First, welded joints were investigated with elaborate load tests supported by numerical analysis. Second, the mechanical properties of a wide variety of microstructures caused by welding heat input were determined through thermo-mechanical analysis. The results of this work contribute to a better understanding of the development of mechanical properties in HAZ and make it possible to provide realistic material models for structure-mechanical investigations using the finite element method. In particular, the aim of the present project was to use the obtained results for the representation of the material characteristics of welded aluminium cross joints and to predict their limit load behaviour with numerical simulations.

\section{Materials and Methods}

\subsection{Investigated Aluminium Alloy}

The experiments of this study were performed on a wrought aluminium alloy, EN AW-6082 (BIKAR-Aluminium GmbH, Korbußen, Germany), which was supplied as a $10 \mathrm{~mm}$ thick plate in the initial state T651. According to DIN EN 515 the treatment T651 includes solution annealing, quenching, stretching by $1.5 \%$ to $3 \%$ and subsequent artificial aging. EN AW-4047 (MTC GmbH, Meerbusch, Germany) was used as welding filler material for welding specimens. The chemical composition of EN AW-6082 and fusion zone material of a butt joint determined with optical emissions spectroscopy (OES) is given in Table 1 in addition to the specifications from DIN EN 573-3 [7].

Table 1. Mass fraction of alloying elements in the investigated EN AW-6082 alloy, fusion zone material of a butt joint and weld filler material EN AW-4047, in percent.

\begin{tabular}{ccccccccc}
\hline Material/alloy & Source & Si & Fe & Cu & Mn & Mg & Cr & Zn \\
\hline EN AW-6082 & OES & 0.83 & 0.38 & 0.06 & 0.48 & 0.92 & 0.03 & 0.01 \\
EN AW-6082 & DIN EN 573-3 & $0.7-1.3$ & $\leq 0.5$ & $\leq 0.1$ & $0.4-1.0$ & $0.6-1.2$ & $\leq 0.25$ & $\leq 0.2$ \\
EN AW-4047A & DIN EN 573-3 & $11-13$ & 0.6 & 0.3 & 0.15 & 0.1 & - & $\leq 0.2$ \\
Fusion zone material & OES & 7.23 & 0.29 & 0.03 & 0.19 & 0.39 & 0.02 & $<0.01$ \\
\hline
\end{tabular}

Table 2 shows the mechanical properties in three different directions (rolling direction $0^{\circ}, 45^{\circ}$ and $90^{\circ}$, as in [8]) of the base material determined from tensile tests. A comparison with the standard shows that the properties of the base material fit or exceed the required values in all directions. The differences between the directions in the present rolled plate material are negligible compared to the differences in extruded material (e.g., Chen et al. [9]). Thus, isotropic behaviour can be assumed [10]. In this study, the mechanical properties from the $0^{\circ}$-specimens are used for the base material. 
Table 2. Mechanical Properties of EN AW-6082 T651 depending on the rolling direction.

\begin{tabular}{ccccc}
\hline Rolling Direction & $\boldsymbol{E}\left(\mathbf{N} / \mathbf{m m}^{2}\right)$ & $\boldsymbol{R}_{\mathbf{m}}\left(\mathbf{N} / \mathbf{m m}^{2}\right)$ & $\boldsymbol{R}_{\mathbf{p} \mathbf{0 . 2}}\left(\mathbf{N} / \mathbf{m m}^{2}\right)$ & $\boldsymbol{A}_{\mathbf{5}}(\mathbf{\%})$ \\
\hline $0^{\circ}$ & 70800 & 308 & 289 & 12.2 \\
$45^{\circ}$ & 70000 & 303 & 278 & 13.0 \\
$90^{\circ}$ & 71300 & 308 & 284 & 11.5 \\
\hline Max. Difference & $1.8 \%$ & $1.5 \%$ & $3.8 \%$ & $11.8 \%$ \\
DIN EN 485-2 [11] & 70000 & 300 & 255 & 9 \\
\hline
\end{tabular}

Furthermore, for different methods investigating the material behaviour several different samples were used. Table 3 gives an overview of the different specimen geometries and dimensions.

Table 3. Overview on used samples.

\begin{tabular}{cccc}
\hline Method & Previous Treatment & Geometry & Dimensions in mm \\
\hline Temperature measurement & Initial state & T-joint & $240 \times 160 \times 10$ plus $240 \times 71 \times 10$ \\
DSC, heat flow & Initial state & Cylindrical & $\varnothing 6 \times 21.65$ \\
DSC, power compensated & Initial state & Cylindrical & $\varnothing 6.4 \times 1$ \\
TMA & Initial state & Cylindrical & $\varnothing 5 \times 10$ \\
Tensile tests & Initial state & Cylindrical ** & $\varnothing 8 \times 48$ \\
Tensile tests & Butt welded & Cylindrical $^{* *}$ & $\varnothing 6 \times 36$ \\
Tensile tests, DIC & Butt welded & Flat specimen & $25 \times 6(\mathrm{~B} \times \mathrm{T})$, smooth, R40, R10 \\
\hline
\end{tabular}

${ }^{*}$ see Figure $2,{ }^{* *}$ see Figure 4.

The high strengths in aluminium alloys are achieved in particular by precipitation hardening [12]. The precipitation sequence of Al-Mg-Si alloys was described by Edward and Dutta et al. $[13,14]$. An overview of these precipitates with information on dimensions, coherence, shape and further remarks was given by Polmear [15]. In Al-Mg-Si alloys, the beta phase results in maximum strengths [13].

The precipitation behaviour of several Al-Mg-Si alloys during cooling was investigated with DSC and microstructure analysis (optical microscopy (OM), SEM and TEM) [16-19]. Two different reaction areas, high (HTR) and low temperature reactions (NTR), were detected. In part, there is also a third middle temperature reaction (MTR). The high temperature reactions were correlated with the precipitation of $\mathrm{Mg}_{2} \mathrm{Si}$ and the low temperature reactions of the precipitation of precursor phases. Precipitation behaviour depend strongly on initial state and chemical composition The critical cooling rate of 6082 can vary by factor of 10 depending on $\mathrm{Mg}$ and Si content [20].

In [21], the precipitation behaviour of the same batch of 6082 in the same initial state as in this study was analysed depending on different annealing conditions. The precipitation behaviour depends above all on whether there is a complete or incomplete dissolution of secondary particles at the onset of cooling.

The dissolutions and precipitations of Al-Mg-Si alloys during heating were also analysed with DSC and it was linked to the mechanical properties by TMA [5,21,22]. Osten et al. [21] investigated the dissolution and precipitation behaviour of several Al-Mg-Si alloys, including 6082, in various initial states during heating and has assigned the measured peaks to specific reactions through extensive literature research.

\subsection{Welding Procedure and Temperature Measurements}

Considering the aim of the project, butt welded joints and T-joints were used (see Figures 1 and 2), which were processed manually with metal inert gas welding (MIG) with three and four beads, respectively. Plates of EN AW-6082 T651 were welded with EN AW-4047 (wire diameter $1.2 \mathrm{~mm}$ ) as weld filler material. Welding was conducted with direct current and positive polarity. A mixture of 
argon and helium (70\%/30\%) was applied as shielding gas. A ceramic weld pool backing was used for all joints. Further welding parameters are listed in Table 4.

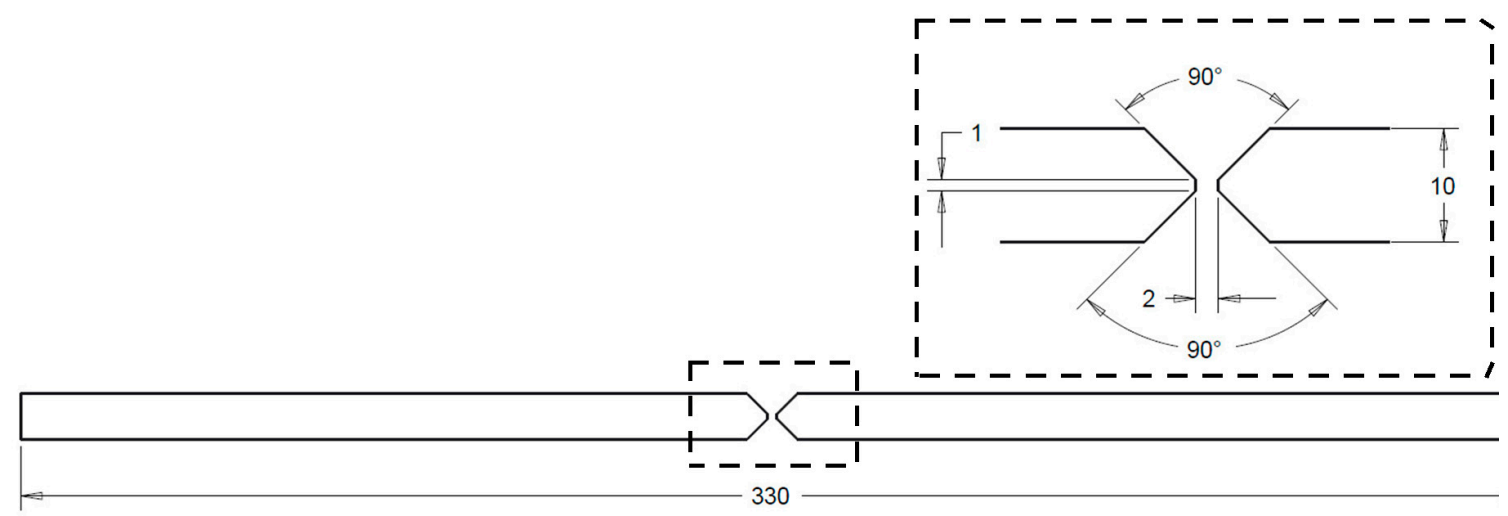

Figure 1. Prepared plates for butt welding, length of plates was $500 \mathrm{~mm}$, lengths in $\mathrm{mm}$.

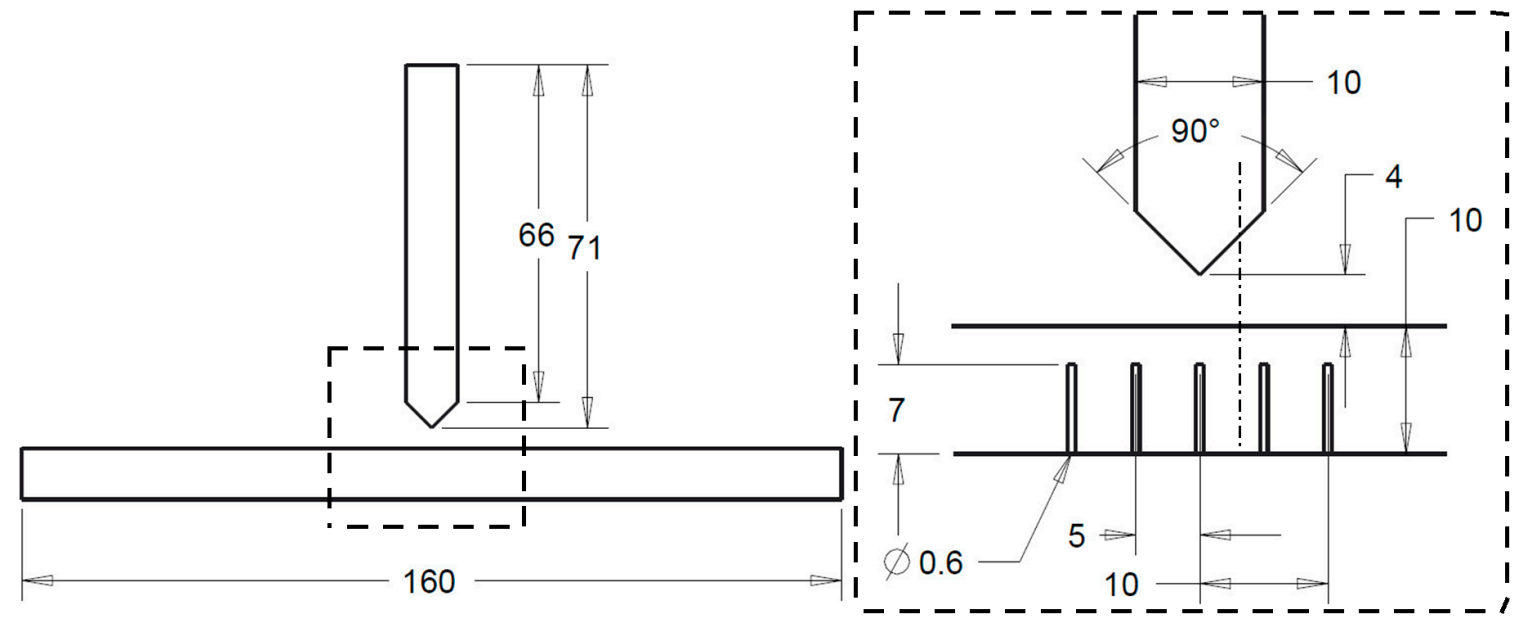

Figure 2. Sketch of prepared T-joint including drill holes for thermocouples, lengths in mm.

Table 4. Welding parameters of EN AW-6082 plates.

\begin{tabular}{cccccc}
\hline Joint & Welding Bead & Current (A) & Voltage (V) & Wire Feed (m/min) & Wire Diameter (mm) \\
\hline \multirow{2}{*}{ Butt joint } & 1 & 145 & 23.5 & 7.5 & 1.2 \\
& $2 \& 3$ & 145 & 23.5 & 7.5 & 1.2 \\
T-joint & $1 \& 2$ & 204 & 24.4 & 9.5 & 1.2 \\
& $3 \& 4$ & 188 & 23.7 & 8.5 & 1.2 \\
\hline
\end{tabular}

A temperature-time course in the heat-affected zone during a real welding process is needed as input data for differential scanning calorimetry and for thermo-mechanical analysis. Eight thermocouples (Type K, $0.5 \mathrm{~mm}$, Therma Thermofühler $\mathrm{GmbH}$, Lindlar, Germany) that were completely inserted in drilled holes simultaneously measured the temperature with a frequency of $50 \mathrm{~Hz}$. The geometry of the prepared aluminium sheets is displayed in Figure 2 including the positions of the holes for thermocouples. The diameter of the holes was $0.6 \mathrm{~mm}$, slightly larger than the diameter of thermocouple wire, to ensure that the thermocouples could be positioned at the end of drilled holes. The length of this T-joint was $240 \mathrm{~mm}$ and the thermocouple holes were drilled lengthwise at 80 and $160 \mathrm{~mm}$ from the edge. 


\subsection{Differential Scanning Calorimetry}

The heating rate range of $0.01-5 \mathrm{~K} \mathrm{~s}^{-1}$ was investigated by direct DSC with two types of calorimeters: CALVET-type heat-flux DSC (DSC 121 and Sensys, Setaram, Caluire-et-Cuire, France) for slower (0.01-0.1 K s${ }^{-1}$ ) and power-compensated DSC for faster $\left(0.3-5 \mathrm{~K} \mathrm{~s}^{-1}\right)$ scanning rates (Pyris Diamond and Pyris DSC 8500, PerkinElmer, Waltham, MA, USA). The samples used for heat-flux DSC had a cylindrical geometry with $6 \mathrm{~mm}$ diameter, $21.65 \mathrm{~mm}$ height and a mass of $1600 \mathrm{mg}$. Cylindrical samples with $6.4 \mathrm{~mm}$ diameter, $1 \mathrm{~mm}$ height and a mass of $80 \mathrm{mg}$ were investigated in the power-compensated DSC devices. All experiments were carried out with an alloyed sample in one micro furnace and a pure-aluminium reference $(99.9995 \%$ purity) with the same geometry in the other micro furnace. The samples and references were packed in pure-aluminium crucibles.

For investigation of very fast heating rates, which are typical for the HAZ during welding, direct DSC cannot be used, because the heating rate limit of the devices is exceeded. Instead, the indirect DSC method was used. Zohrabyan et al. [23] developed the differential reheating method to extend the temperature rate range. The schematic procedure of this method is shown in Chapter 3.2 together with its results. Rapid heating took place in the quenching dilatometer Bähr $805 \mathrm{~A} / \mathrm{D}$ (BÄHR Thermoanalyse GmbH, Hüllhorst, Germany). The device is explained in Chapter 2.4. For indirect DSC, the samples had the same geometry (diameter of $6.4 \mathrm{~mm}$, height of $1 \mathrm{~mm}$, mass of $80 \mathrm{mg}$ ) as for direct DSC in the power-compensated devices. The samples were heated with rates from 20 to $100 \mathrm{~K} \mathrm{~s}^{-1}$ to temperatures of $200{ }^{\circ} \mathrm{C}$ to $450{ }^{\circ} \mathrm{C}$, respectively, with an interval of $25 \mathrm{~K}$. To preserve the state of the material at the maximum temperature, the samples were immediately quenched with maximum gas flow from He. After heat treatment, the samples were directly frozen at $-80^{\circ} \mathrm{C}$ until being reheated in the DSC device.

Reheating in the DSC device was performed with a scanning rate of $1 \mathrm{~K} \mathrm{~s}^{-1}$ to a maximum temperature of $575^{\circ} \mathrm{C}$.

The data processing of raw measured heat flow curves applied in this study was described in detail by Fröck et al. [24]. To obtain high-quality DSC results, the following sequence of experiments was conducted: sample measurement-baseline measurement, sample measurement. This is an efficient method to obtain a baseline for each sample measurement immediately. Baseline measurements were carried out with two pure aluminium references in the micro furnaces and the same temperature program as for the sample measurements. Baseline measurements were made to ascertain the current device specific curvature, which can change significantly within hours. This curvature is removed by subtracting the baseline determined in a timely manner.

The comparison of DSC curves of different sample masses $m_{\mathrm{s}}$ and scanning rates $\beta$ requires a normalisation of the measured heat flow signal. For this reason, the specific heat capacity $c_{p_{\text {excess }}}$ [25] is calculated according to:

$$
c_{p_{\text {excess }}}=\frac{\dot{Q}_{\mathrm{s}}-\dot{Q}_{\mathrm{BL}}}{m_{\mathrm{s}} \beta}\left(\text { in J.g }{ }^{-1} \cdot \mathrm{K}^{-1}\right)
$$

with heat flow of baseline $\dot{Q}_{\mathrm{BL}}$ and sample measurement $\dot{Q}_{\mathrm{s}}$.

Remaining artefacts such as overshoots at the start and end of a scanning step were removed. The residual curvature of $c_{\mathrm{p}_{\text {excess }}}$-curves can be compensated for with a polynomial fit. This was applied only for heating curves with scanning rates of $0.01 \mathrm{~K} \mathrm{~s}^{-1}$ and $0.03 \mathrm{~K} \mathrm{~s}^{-1}$, because, for this data processing step, reaction free zones at low and high temperatures are necessary $[4,21]$.

The slow heating experiments $\left(0.01-0.1 \mathrm{~K} \mathrm{~s}^{-1}\right)$ consist of 4-6 sample measurements and 2-3 baselines. In the heating rate range of $0.3-5 \mathrm{~K} \mathrm{~s}^{-1}$, eight sample measurements and four baselines were performed for each scanning rate. For indirect DSC, four sample measurements and two baselines for each maximum temperature and each heating rate were conducted. The average curves of these experiments are plotted in the diagrams. In total, more than 220 DSC experiments were performed. 


\subsection{Thermo-Mechanical Analysis and Hardness Testing}

Thermo-mechanical analysis measures the deformation of a material under compression or tension as a function of temperature. To analyse the mechanical properties of the aluminium alloy 6082 T651 depending on the parameters of a thermal welding cycle, a thermo-mechanical analysis has been performed in the quenching and deformation dilatometer type Bähr $805 \mathrm{~A} / \mathrm{D}$. A schematic of the cylindrical compression sample inside the testing machine is shown in Figure 3. During the investigation, the specimens with geometrical dimensions of $\varnothing 5 \mathrm{~mm} \times 10 \mathrm{~mm}$ are heated inductively by the surrounding induction coil. An additional perforated inner coil was used for inert gas cooling. The temperature of the specimen was controlled with thermocouples spot-welded onto the specimen surface. The samples retrace the temperature-time profiles, which were measured in the HAZ during welding. The compression tests were carried out after seven days natural aging at about $20^{\circ} \mathrm{C}$ with a deformation rate of $1 \mathrm{~mm} / \mathrm{s}$. Thereby, force-displacement curves were recorded. Every combination of heating rate and temperature was repeated three or four times and revealed a good reproducibility. The determined load-displacement diagrams were evaluated to flow curves representing true stresses and true strains.

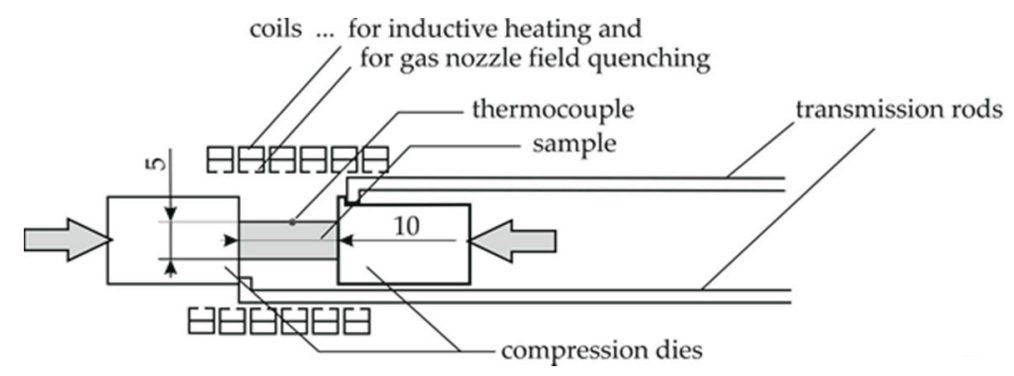

Figure 3. Schematic of cylindrical compression sample inside quenching and deformation dilatometer type Bähr 805 A/D.

During the evaluation of the compression tests, the absolute values of forces and displacements are calculated so that only positive strains and stresses are shown in the diagrams. These data can be compared directly with the results of the tensile tests.

For the hardness curve over the cross-section of weld seams, hardness values (HV1) were ascertained with the micro hardness tester HMV-2 from Shimadzu, Kyoto, Japan.

\subsection{Tensile Tests on Welded Joints}

To obtain the mechanical properties of the fusion zone (FZ), tensile tests on round specimens were conducted. The specimens had a diameter of $6 \mathrm{~mm}$ and were machined out of a V-shaped butt weld. Due to manufacturing limitations this specimen contained not only the weld material, but also small parts of the heat affected zone. Therefore, the results of these tests must be seen as integral values of the fusion zone and adjacent heat affected zone material. The displacements were measured by an extensometer.

To determine the mechanical behaviour of the heat affected zone, tensile tests on whole welded joints were conducted. Two plates of the base material were joined with an X-shaped butt weld, as described in Chapter 2.2. To obtain flat specimens the $10 \mathrm{~mm}$ thick welded plates were milled to $6 \mathrm{~mm}$ thickness (Figure 4a). Smooth and notched specimens (notch radius of $10 \mathrm{~mm}$ and $40 \mathrm{~mm}$, Figure $4 \mathrm{~b}$ ) with a width of $25 \mathrm{~mm}$ in the smallest cross section were manufactured. Displacements and strains on the surface of the flat specimens were measured with a 2D digital image correlation system. Therefore, the surface of the specimens was prepared with a speckle pattern. The camera resolved the surface with a pixel size of $0.03 \mathrm{~mm}$. The majority of the speckles had a size of $2 \times 2$ to $4 \times 4$ pixels. The data was processed with the software VIC 2D 6 (Correlated Solutions, Irmo, SC, USA). 


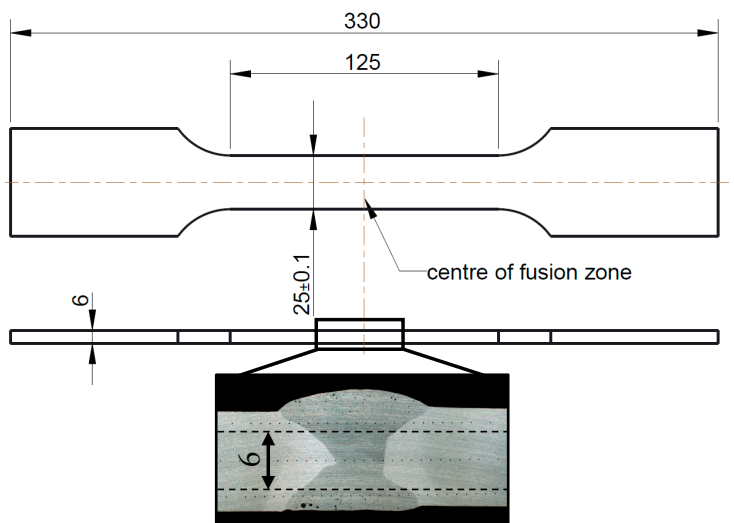

(a)

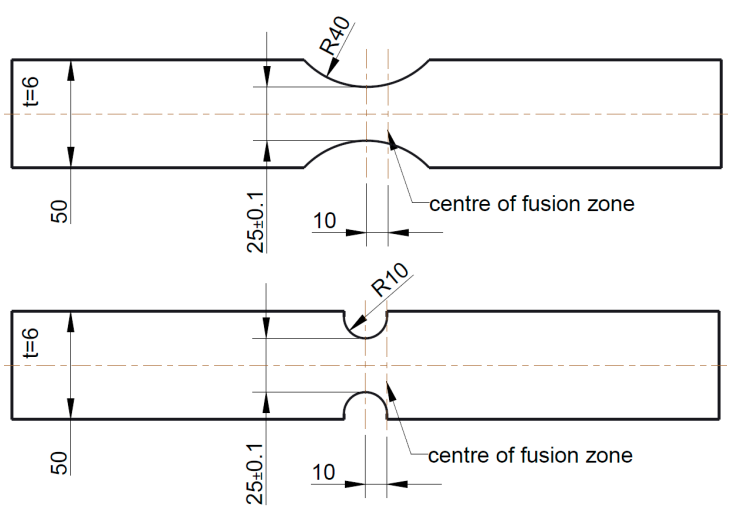

(b)

Figure 4. Geometries of the (a) smooth and (b) notched butt welded flat specimen for investigation of the HAZ, lengths in mm.

The DIC offers the possibility to place several virtual extensometers on the specimen surface with a freely chosen length. Therewith, force-displacement curves of several zones of the specimen can be obtained. The dimensions of the zones were first derived from hardness measurements and then compared with the DSC and TMA experiments.

For this investigation, the specimen was divided into four areas of interest: fusion zone and three areas in the heat affected zone (Z1, Z2 and Z3). Z3 was chosen such that differences with the base material (BM) are small and therefore the properties of the BM can be assumed (see hardness measurements in Chapter 3.3). Necking and fracture of the specimen was expected in Z1. Z2 filled the area between $\mathrm{Z} 1$ and $\mathrm{Z} 3$.

With the virtual extensometers, the force-displacement curves of each individual material zone were measured along with a global force-displacement curve including all zones. For the global curve, the virtual extensometer had a base length of $65 \mathrm{~mm}$, whereas the extensometers of $\mathrm{Z} 1$ and Z2 were applied over the whole zone length of $12 \mathrm{~mm}$ and $9 \mathrm{~mm}$, respectively. Accurate strain measurements can be achieved with the virtual extensometers due to their undeformed length of at least 300 pixels. Material properties from Z1 and Z2 can be obtained with this method without manufacturing separate specimens.

\subsection{Determination of True Stress-Strain Curves}

Tensile tests can be evaluated to determine the flow curve of a material. As long as uniform elongation occurs in the tests, the flow curve (equivalent von Mises strain $\sigma_{\mathrm{vM}}$ over total equivalent plastic strain $\varepsilon_{\mathrm{pl}}$ ) can be calculated analytically as follows. First, the true strain $\varepsilon$

$$
\varepsilon=\ln \left(1+\varepsilon_{\mathrm{e}}\right)
$$

and true stress $\sigma$

$$
\varepsilon=\sigma_{\mathrm{e}}\left(1+\varepsilon_{\mathrm{e}}\right)
$$

can be calculated from the engineering stresses $\sigma_{\mathrm{e}}$ and engineering strains $\varepsilon_{\mathrm{e}}$. In this case, the true stress equals the von Mises equivalent stress $\sigma_{\mathrm{vM}}$. The plastic strain $\varepsilon_{\mathrm{pl}}$ can be calculated by

$$
\varepsilon_{\mathrm{pl}}=\varepsilon-\frac{\sigma}{E}
$$


After onset of necking of the specimen, the stress state is not uniaxial anymore. To obtain the flow curves beyond the onset of necking, there are several analytical approaches. One often used method is to fit the values obtained by Equations (3) and (4) with a simple power law of the form

$$
\sigma_{\mathrm{vM}}=K \varepsilon_{\mathrm{pl}}{ }^{n}
$$

Another possibility is to calculate the parameters $K$ and $n$ of Equation (5) with the true stresses $\sigma_{\mathrm{m}}$ and plastic strains $\varepsilon_{\mathrm{m}}$ at the beginning of necking. The power law becomes

$$
\sigma_{\mathrm{vM}}=\sigma_{\mathrm{m}}\left(\frac{\varepsilon_{\mathrm{pl}}}{\varepsilon_{\mathrm{m}}}\right)^{\varepsilon_{\mathrm{m}}} \text { for } \varepsilon_{\mathrm{pl}} \geq \varepsilon_{\mathrm{m}}
$$

and allows an extrapolation of the experimental data beyond the onset of necking.

However, neither method considers experimental results after the start of necking. Therefore, numerical simulations were conducted with the finite element program MarcMentat2013 to obtain flow curves with an iterative procedure. On the one hand, round specimens were simulated with rotational symmetric half models. On the other hand, 3D volume models were used to simulate flat specimens. In contrast to the geometry of the specimens, the deformation of the welded specimens is not symmetric in the tension direction due to strain localisation in the HAZ at one side of the fusion zone. Therefore, a quarter model with symmetry in width and thickness directions was used.

In this iterative procedure, the flow curve of the material is changed in a way that the resultant force-displacement curve in the simulation equals the force-displacement curve of the experiment. The detailed procedure was described by Gannon [25].

This method can be used for the base material and fusion zone material, since specimens with homogenous behaviour are assumed. For the HAZ, this method is not useable without modification, because the flat specimens do not consist of a homogeneous material (see Figure 4a). Furthermore, no necking or failure occurs in the Z2. Accordingly, the experimental stress-strain curve of the Z2 does not reach the tensile strength for this zone and $\sigma_{\mathrm{m}}$ and $\varepsilon_{\mathrm{m}}$ are unknown. Thus, the experimental result for the flow curve of the $Z 2$ is extrapolated with a fitted power law given in Equation (5).

The flow curve of the $Z 1$ can be obtained by iteration, but instead of using one single material the whole specimen with FZ, Z1, Z2 and Z3 (assumed properties of the BM) and their respective flow curves was modelled. The simulation of a complete specimen ensures that the edges of the $\mathrm{Z1}$ behave correctly, because the different strengths of the adjacent $\mathrm{Z} 2$ and fusion zone hinder the deformation in width direction.

\section{Results and Discussion}

\subsection{Temperature-Time Course in Heat Affected Zone}

The cross section of the welded joint, which was used for temperature measurements, is shown in Figure 5 including thermocouple bores. The thermocouple wires were located at the end of the blind holes, so the distance between each weld bead and the points of temperature measurement was determined with these cross-section images. 


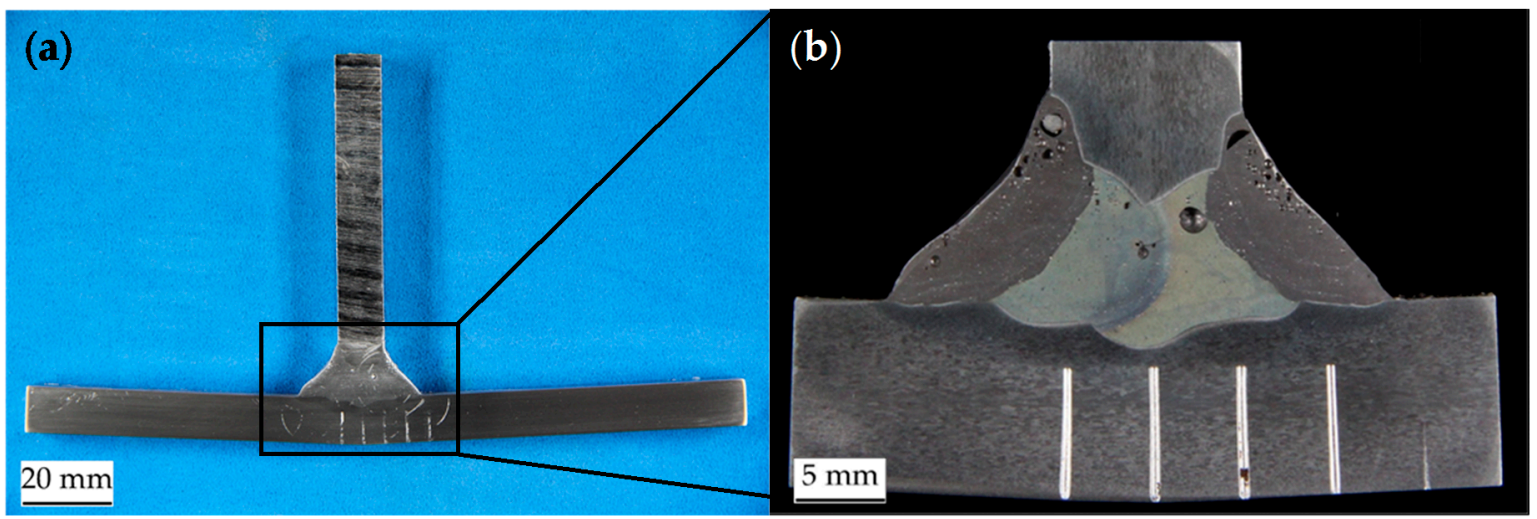

Figure 5. (a) Cross-section of welded T-joint; and (b) macro image of bores for thermocouples.

A typical temperature-time course in HAZ during welding and its three analysed parameters (heating rate, $\mathrm{T}_{\max }$, and cooling rate) are shown in Figure $6 \mathrm{a}$. The heating in all recorded courses was nearly linear over a wide temperature range. The maximum temperature $\left(T_{\max }\right)$ was reached without a holding time and the cooling started immediately with a Newtonian course. Below $200{ }^{\circ} \mathrm{C}$, the temperature decreases very slowly due to the relative small dimensions of joined plates, which heated up significantly. Therefore, only the cooling between $\mathrm{T}_{\max }$ and $200^{\circ} \mathrm{C}$ was used to calculate the mean cooling rate.

(a)

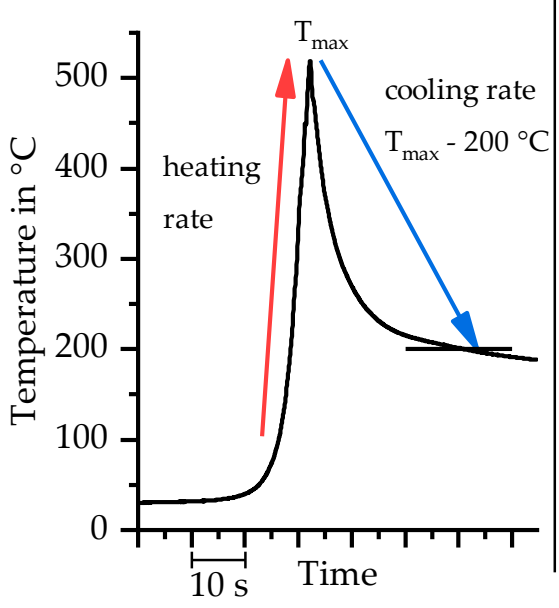

(b)

measured values: parameter of TMA heat treatment:

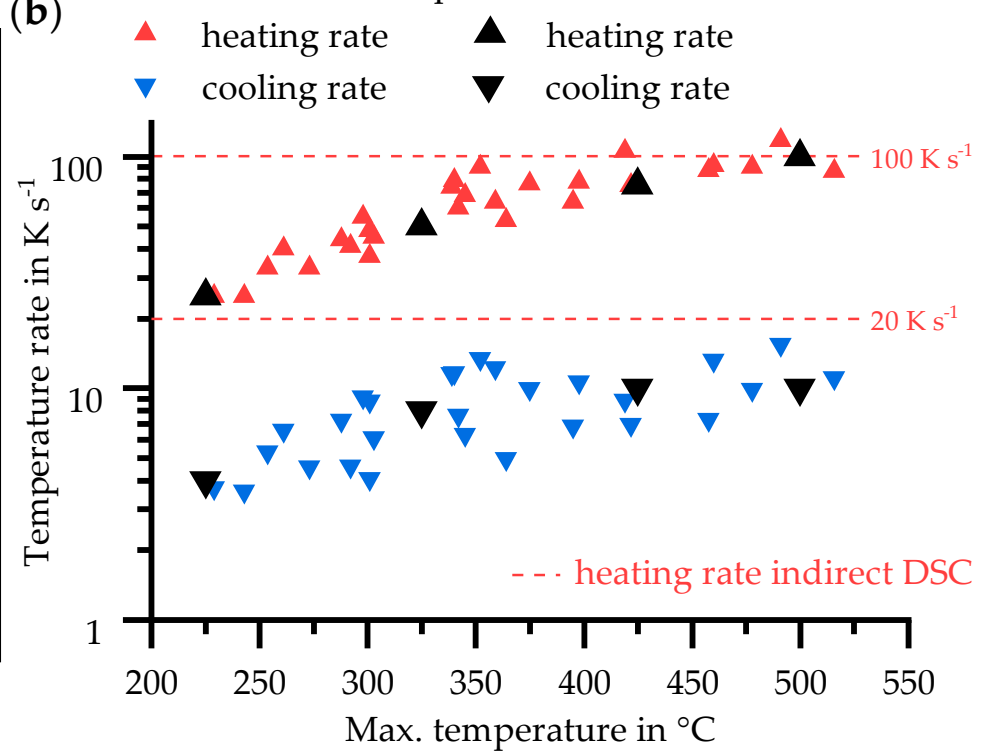

Figure 6. (a) Typical measured temperature-time course in HAZ; and (b) heating and cooling rates in the HAZ during MIG welding of EN AW-6082 depending on the maximum temperature and the resulting parameter of TMA heat treatment as well as the heating rates for indirect DSC.

The analysed heating and cooling rates in the HAZ during welding are plotted against $\mathrm{T}_{\max }$ in Figure $6 \mathrm{~b}$. In principle, the heating and cooling rate increase as the maximum temperature rises, although a scattering of measured values occurs.

The three analysed parameters of temperature measurement revealed: 
- $\quad$ Linear heating rates: $25-118 \mathrm{~K} \mathrm{~s}^{-1}$

- Maximum temperatures $\left(\mathrm{T}_{\max }\right): 229-516^{\circ} \mathrm{C}$

- Averaged cooling rates between $\mathrm{T}_{\max }$ and $200^{\circ} \mathrm{C}: 3.5-15 \mathrm{~K} \mathrm{~s}^{-1}$.

Because the maximum temperature correlates with distance from the fusion zone, these results are also plotted against the distance to weld bead in Figure 7.

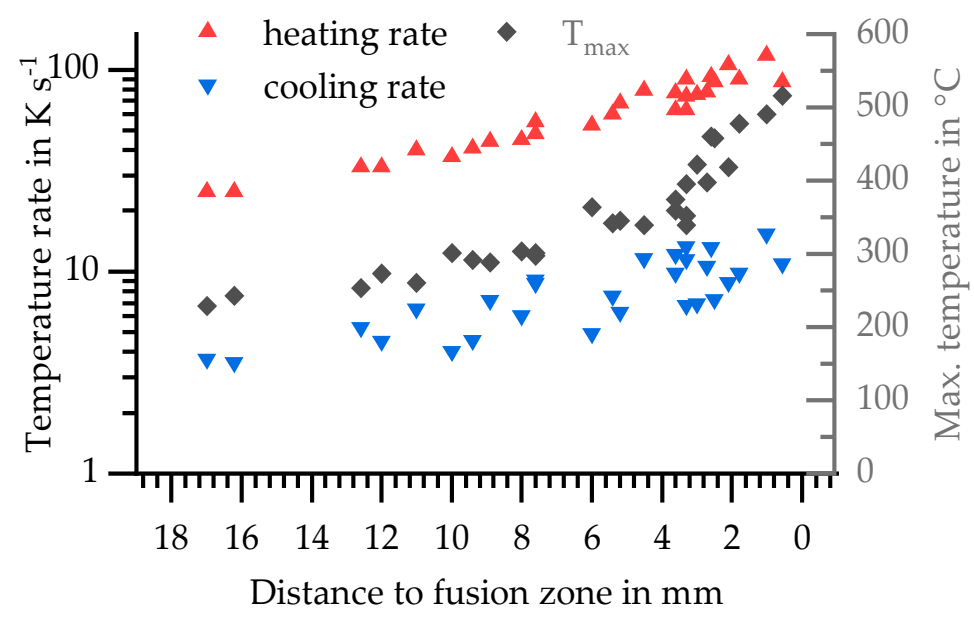

Figure 7. Parameters of temperature-time course dependent on distance to the weld seam.

These results, temperature rates and corresponding maximum temperatures, retrace different positions in the HAZ and were selected as parameters for TMA in this study. They are marked with black symbols in Figure $6 \mathrm{~b}$ and given in Table 5 . The chosen heating rates of indirect DSC $\left(20 \mathrm{~K} \mathrm{~s}^{-1}\right.$ and $100 \mathrm{~K} \mathrm{~s}^{-1}$ ) are in the minimum and maximum range of these values.

Table 5. TMA parameters retracing HAZ.

\begin{tabular}{cccc}
\hline Distance to Fusion Zone & Max. Temperature in ${ }^{\circ} \mathbf{C}$ & Heating Rate in $\mathbf{K ~ s}^{\mathbf{- 1}}$ & ${\text { Cooling Rate in } \mathbf{K ~ s}^{\mathbf{- 1}}}^{\text {Ca. } 2 \mathrm{~mm}}$ \\
Ca. $4 \mathrm{~mm}$ & 500 & 100 & 10 \\
Ca. $8 \mathrm{~mm}$ & 425 & 75 & 10 \\
Ca. $16 \mathrm{~mm}$ & 325 & 50 & 8 \\
& 225 & 25 & 4 \\
\hline
\end{tabular}

\subsection{Precipitation and Dissolution Behaviour of EN AW-6082 T651 in a Wide Dynamic Range}

The excess heat capacity curves of heating the alloy EN AW-6082 with initial state T651 over a heating rate range from $0.01 \mathrm{~K} \mathrm{~s}^{-1}$ to $5 \mathrm{~K} \mathrm{~s}^{-1}$ up to $585^{\circ} \mathrm{C}$ are plotted in Figure 8. During heating of aluminium alloys, dissolution and precipitation reactions occur. Precipitations were measured as exothermic peaks and dissolution as endothermic peaks. These reactions are alternating and overlap each other. Thus, the DSC curves show only the resulting sum signal, and only the initial temperature of the first and the final temperature of the last reaction are true signals. 


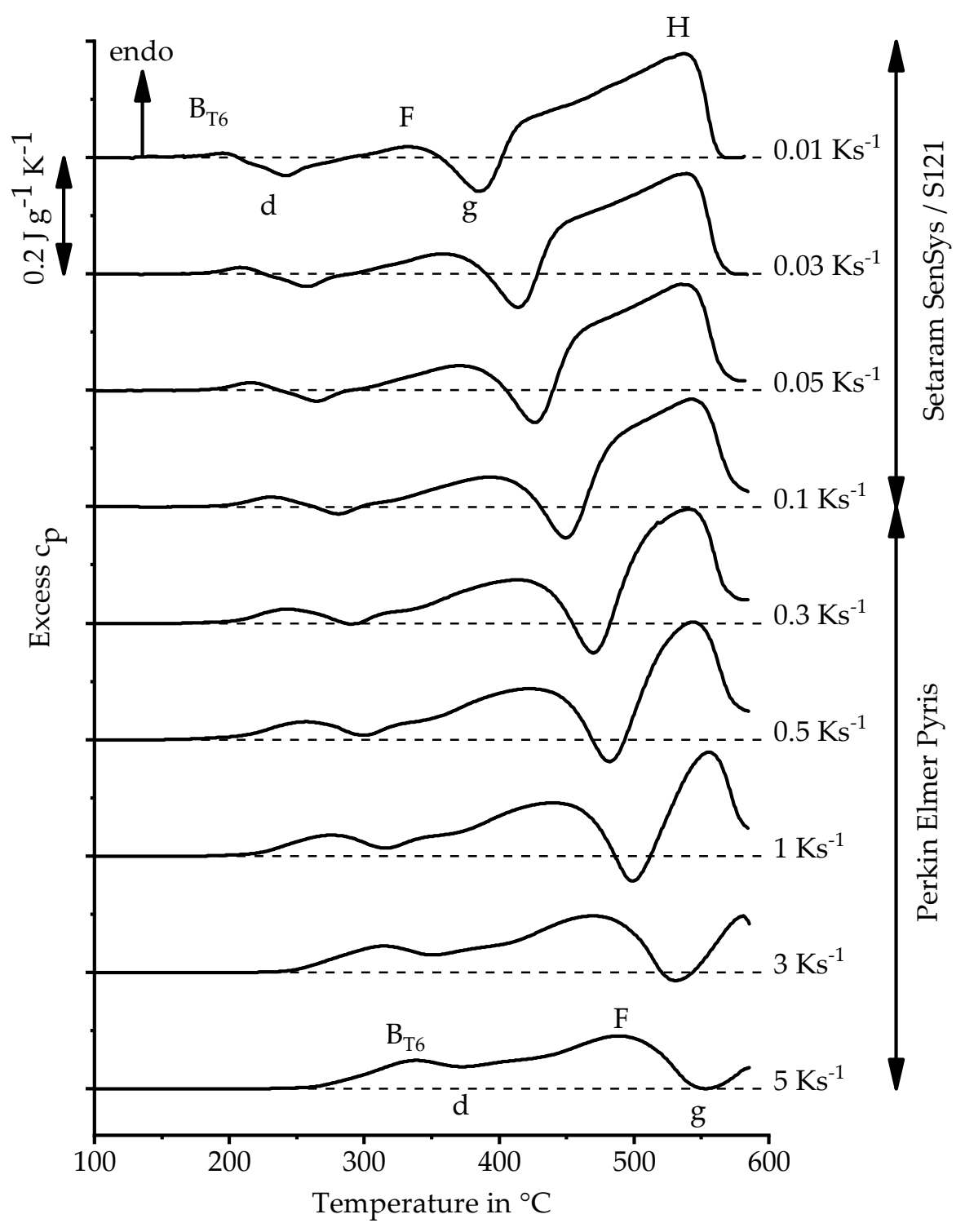

Figure 8. Direct DSC heating curves of EN AW-6082 T651 heating rates $0.01 \mathrm{~K} \mathrm{~s}^{-1}$ to $5 \mathrm{~K} \mathrm{~s}^{-1}$.

The DSC curve recorded by Osten et al. [21] with another batch of EN AW-6082 with a $0.01 \mathrm{~K} \mathrm{~s}^{-1}$ heating rate resembles the curve from this study with the same scanning rate. There are only slight differences in reaction behaviour at slow scanning rates, which can be explained by differences in chemical composition, but the sequence of reactions is the same. Therefore, their interpretation of the reaction sequence is used in this study. The reactions were labelled here with the same characters [21].

The first peak B for the initial state T6 is induced by the dissolutions of GP-zones and $\beta "$, with $\beta$ " being the phase which effects the maximum strengths of Al-Mg-Si alloys [13]. The peak $\mathrm{d}$ corresponds to either the precipitation of $\beta^{\prime \prime}$ or $\beta^{\prime}$ depending on initial state $[13,15]$. For the initial state T651, there is probably only a precipitation of $\beta^{\prime}$, because $\beta^{\prime \prime}$ is already dissolved in the previous reaction. The reactions which cause the peaks $F$ and g belong to the dissolution of $\beta^{\prime}$ and the precipitation of $\beta$ $\left(\mathrm{Mg}_{2} \mathrm{Si}\right)$. The dissolution of the remaining precipitations, especially $\beta\left(\mathrm{Mg}_{2} \mathrm{Si}\right)$, is recorded as final peak $\mathrm{H}$. At very slow heating rates, there is a reaction-free range following peak $\mathrm{H}$, which indicates a complete dissolution of these particles [21].

As the heating rates increase, there is a shift of reactions to higher temperatures, which also results in an incomplete dissolution with fast heating. Furthermore, the curves shift in the endothermic direction. However, it is unlikely that dissolution will increase at faster heating rates. Rather, it can be 
assumed that the shift is thus caused because precipitation reactions are significantly more suppressed than dissolution reactions.

Figure 9a displays the temperature-time course of the indirect DSC method. To maintain the condition at $\mathrm{T}_{\max }$ and to prevent quench-induced precipitation, quenching is performed with maximum gas flow after the first heating. The average cooling rates $\beta$ of the Newtonian cooling course, which depended on the temperature interval considered, are listed in Table 6.

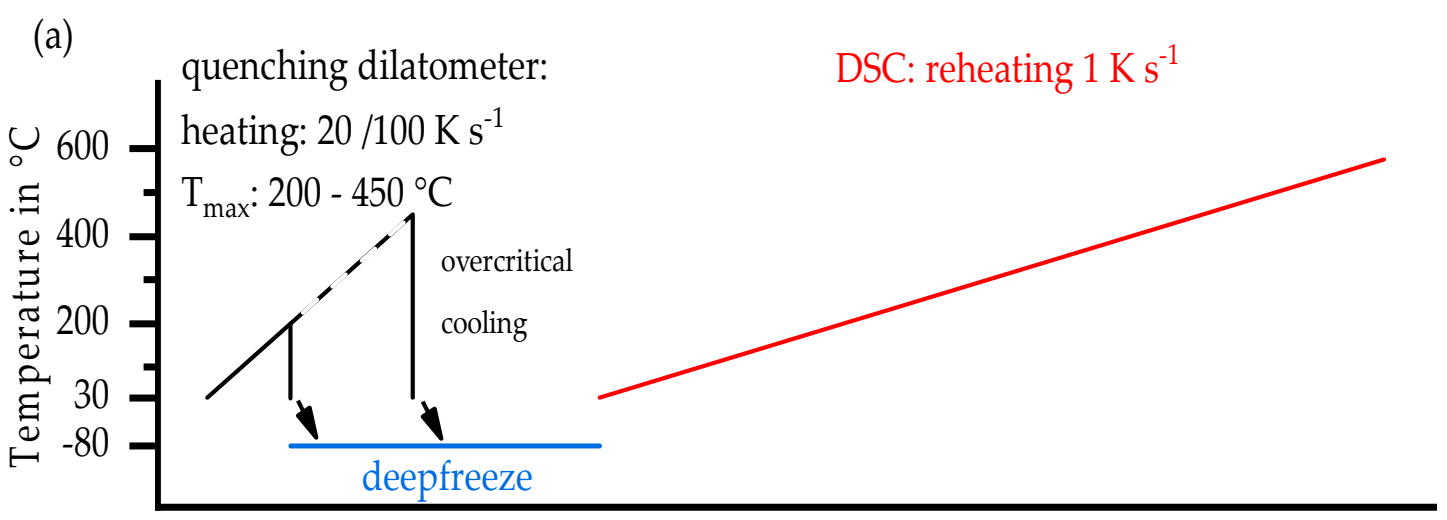

Time

(b) reheating of EN AW-6082: $1 \mathrm{~K} \mathrm{~s}^{-1} 585^{\circ} \mathrm{C}$ heating: $20 \mathrm{~K} \mathrm{~s}^{-1} \mathrm{~T}_{\max }$

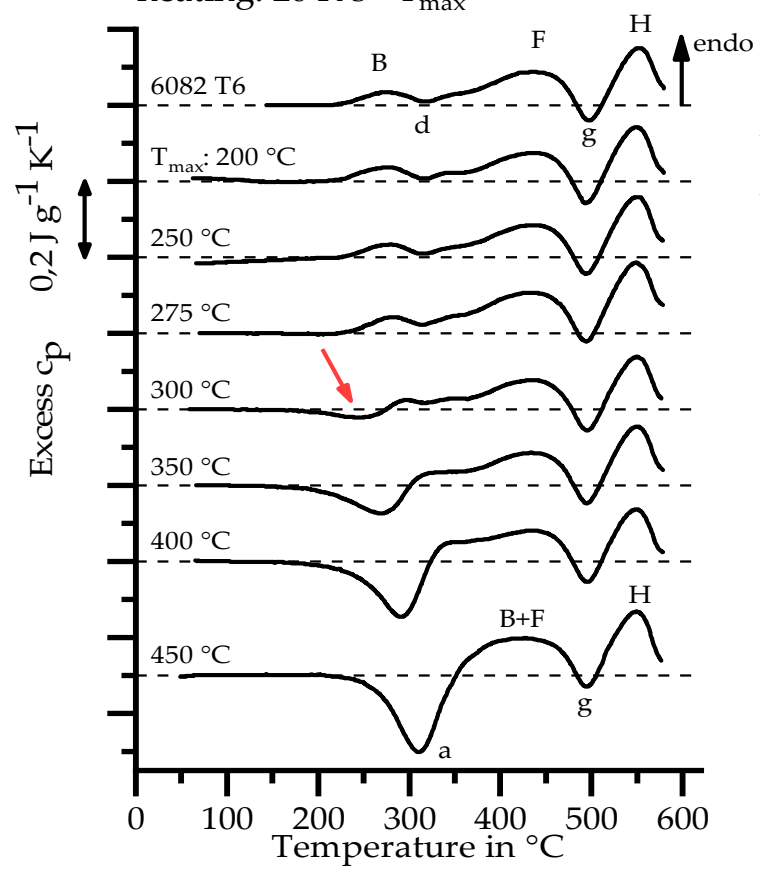

(c) reheating of EN AW-6082: $1 \mathrm{~K} \mathrm{~s}^{-1} 585^{\circ} \mathrm{C}$ heating: $100 \mathrm{~K} \mathrm{~s}^{-1} \mathrm{~T}_{\max }$

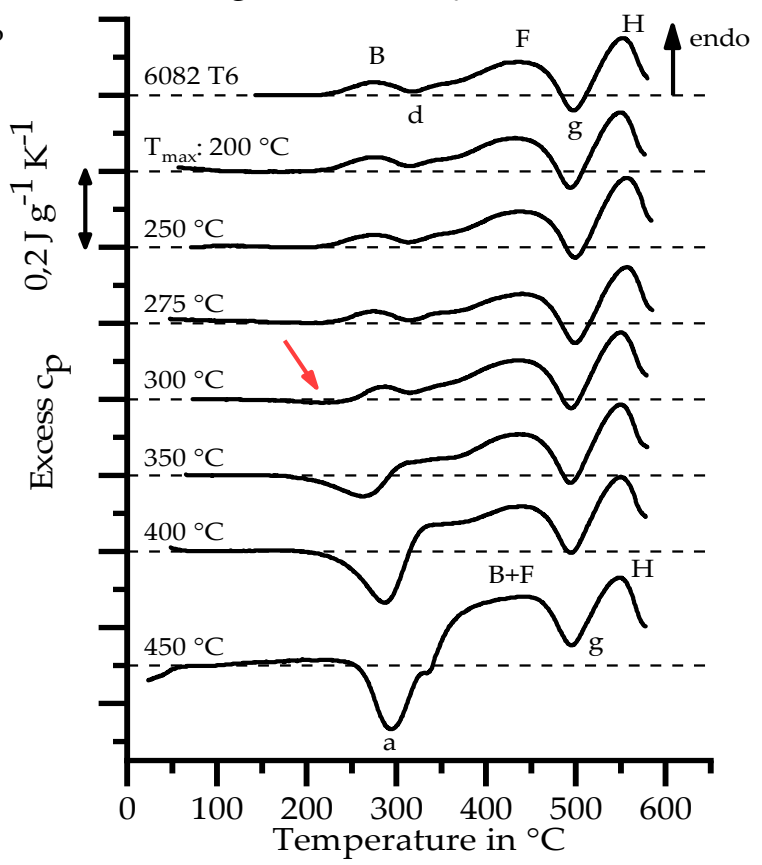

Figure 9. Indirect DSC: (a) schematic temperature-time course; and reheating DSC curves of heating rates: (b) $20 \mathrm{~K} \mathrm{~s}^{-1}$; and (c) $100 \mathrm{~K} \mathrm{~s}^{-1}$.

Table 6. Average cooling rates of heat treatment for indirect DSC.

\begin{tabular}{ccc}
\hline Upper Temperature & Lower Temperature & Average Cooling Rate \\
\hline $450^{\circ} \mathrm{C}$ & $100^{\circ} \mathrm{C}$ & $\sim 200 \mathrm{~K} \mathrm{~s}^{-1}$ \\
$200^{\circ} \mathrm{C}$ & $100^{\circ} \mathrm{C}$ & $\sim 120 \mathrm{~K} \mathrm{~s}^{-1}$ \\
$100^{\circ} \mathrm{C}$ & $30^{\circ} \mathrm{C}$ & $>32 \mathrm{~K} \mathrm{~s}^{-1}$ \\
\hline
\end{tabular}


Fröck et al. [24] used the same batch of 6082 to investigate the influence of different solution conditions on the precipitation behaviour during subsequent cooling. For an incomplete solution state (after $540{ }^{\circ} \mathrm{C}$ for $1 \mathrm{~min}$ ), the upper critical cooling rate (uCCR) of $100 \mathrm{~K} \mathrm{~s}^{-1}$ was ascertained. The cooling rates of the heat treatment for indirect DSC are higher than this UCCR in temperature ranges above $100{ }^{\circ} \mathrm{C}$. It can thus be assumed that no significant precipitation reactions took place during cooling and the state of the material reached at maximum temperature remains.

The reheating curves are shown in Figure $9 b, c$. The reaction peaks are given the same characters as in Figure 8. Low curvature is present in the curves, which can give reasons for slight quantitative differences between single curves. This is particularly apparent at higher temperatures, e.g., the peaks $\mathrm{g}$ and $\mathrm{H}$, or the slope of reaction free zone are influenced by this remaining curvature. Nevertheless, the development of reactions is clearly visible. The reheating curves of the investigated heating rates $20 \mathrm{~K} \mathrm{~s}^{-1}$ and $100 \mathrm{~K} \mathrm{~s}^{-1}$ show no significant differences for the same $\mathrm{T}_{\max }$. Depending on $\mathrm{T}_{\max }$, there is a substantial development in the reheating curves for each heating rate. In conclusion, the reactions taking place in the HAZ are mainly dependent on $\mathrm{T}_{\max }$ and are less dependent on the heating rate, at least in the investigated range.

The reheating curves from the initial state EN AW-6082 $\mathrm{T} 651$ to $\mathrm{T}_{\max }$ of $275^{\circ} \mathrm{C}$ are almost identical. That means no significant reactions take place until heating to this temperature. From $\mathrm{T}_{\max } 300{ }^{\circ} \mathrm{C}$ an exothermic reaction starts (see arrows in Figure $9 b, c$ ). These reaction peaks increase with a higher maximum temperature of first heating. During the first heating, existing precipitates are dissolved increasingly with rising temperature. A supersaturation occurs due to overcritical cooling, which causes the measured precipitation reactions during reheating. This dissolution reaction $\mathrm{B}_{\mathrm{T} 651}$ during rapid heating is crucial for softening in the HAZ.

The reaction peaks determined by direct DSC and the dissolution reaction $\mathrm{B}_{\mathrm{T} 651}$ determined by indirect DSC are plotted in temperature-time courses of investigated heating experiments, to create a continuous heating dissolution diagram for a wide range of heating rates, as shown in Figure 10.

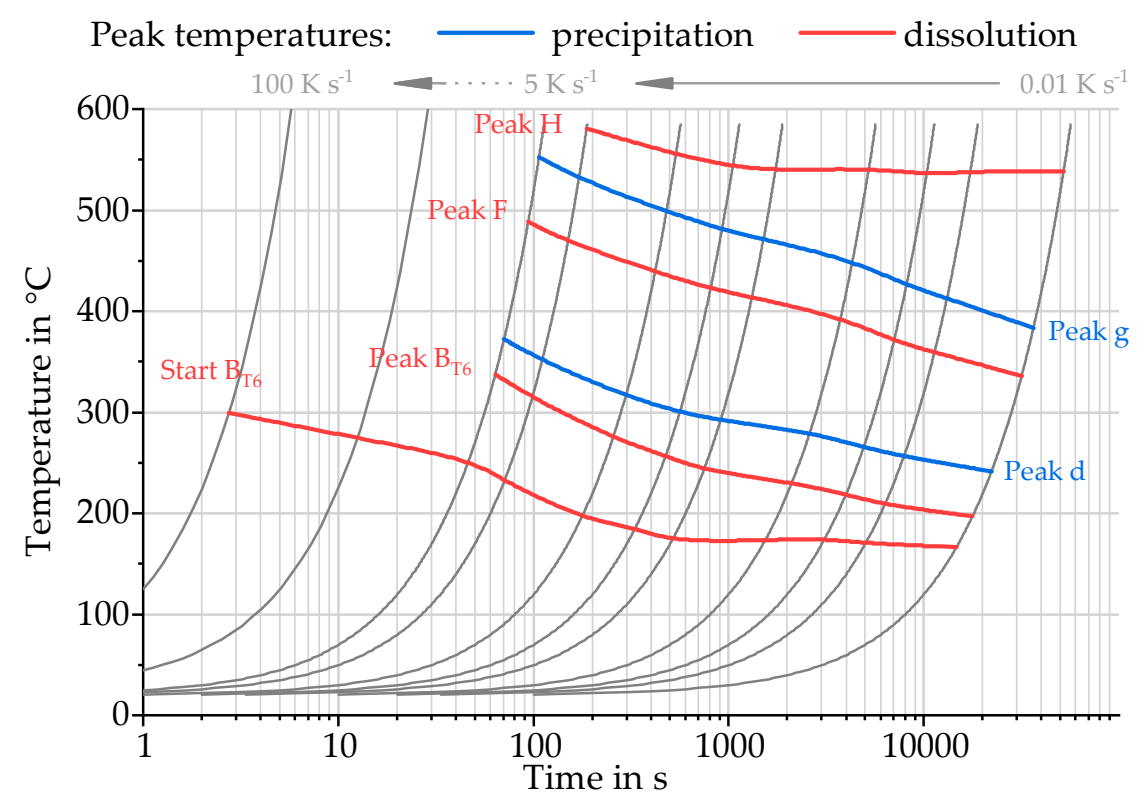

Figure 10. Continuous heating dissolution diagram EN AW-6082 $\mathrm{T} 651$ heating rates $0.01 \mathrm{~K} \mathrm{~s}^{-1}$ to $100 \mathrm{~K} \mathrm{~s}^{-1}$.

The temperatures of dissolution or precipitation reactions during heating of EN AW-6082 T651 within a range of $0.01 \mathrm{~K} \mathrm{~s}^{-1}$ to $100 \mathrm{~K} \mathrm{~s}^{-1}$ can be taken from this diagram. For heating of $20 \mathrm{~K} \mathrm{~s}^{-1}$ to $100 \mathrm{~K} \mathrm{~s}^{-1}$, investigated with indirect DSC, only the start of the dissolution reaction $\mathrm{B}_{\mathrm{T} 651}$ can be determined at temperatures between $275^{\circ} \mathrm{C}$ and $300{ }^{\circ} \mathrm{C}$. 


\subsection{Mechanical Properties of the HAZ}

The results of hardness tests in Figure 11 provide an overview of properties as a function of distance to the weld centre. At a distance from the weld centre of more than $50 \mathrm{~mm}$ a constant hardness of about $100 \mathrm{HV} 1$ was measured in the base material $6082 \mathrm{~T} 651$. At about $40 \mathrm{~mm}$, a maximum hardness of $110 \mathrm{HV} 1$ is reached. One reason for the increase in hardness may be that the initial state T651 was slightly underaged and the welding heat causes artificial ageing at this point. With decreasing distance, the hardness decreases significantly to a minimum of about $60 \mathrm{HV} 1$. The hardness increases in the direct vicinity of the FZ. Hardness of the FZ was about 70-80 HV1.

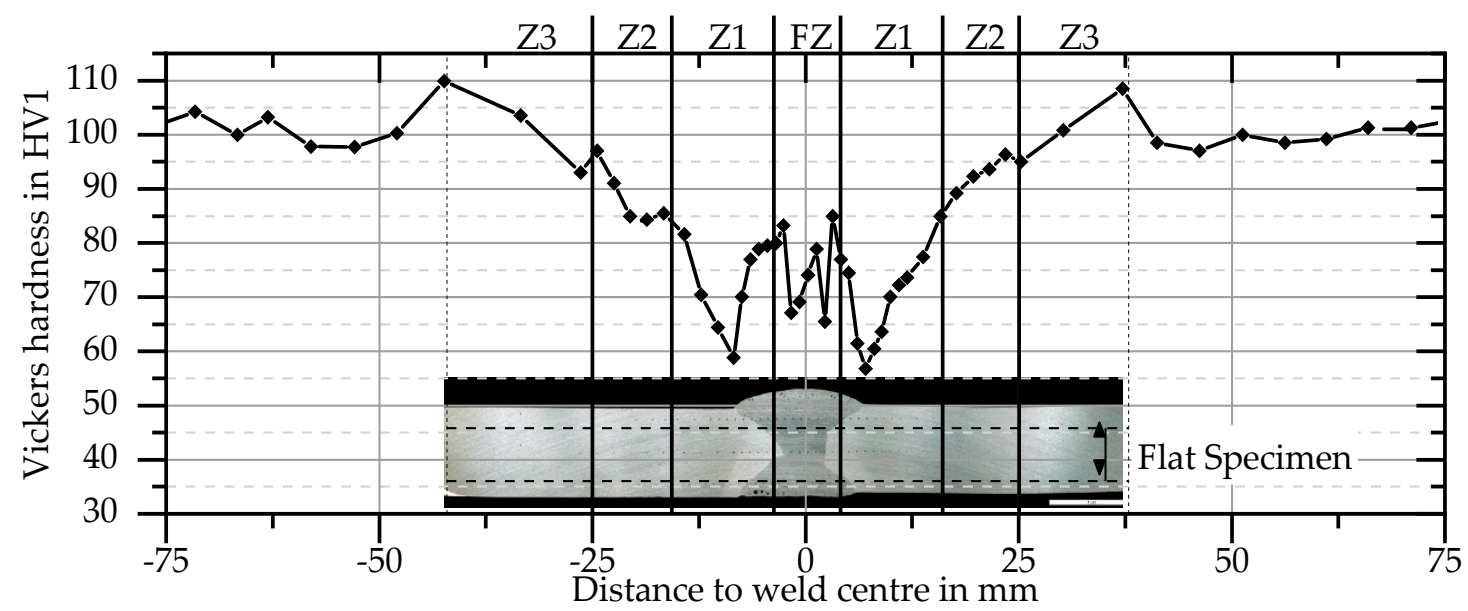

Figure 11. Hardness after welding and natural aging in plate centre.

In Figure 12, the results of TMA with parameters according to Table 5 are plotted against $\mathrm{T}_{\max }$ for the short term heat treatment. The yield strength has been measured after seven days of natural ageing. Compared with the initial state, there is a small increase for $\mathrm{T}_{\max } 225^{\circ} \mathrm{C}$. From $\mathrm{T}_{\max } 225^{\circ} \mathrm{C}$ to $425^{\circ} \mathrm{C}$, the yield strength decreases by about half to less than $130 \mathrm{~N} / \mathrm{mm}^{2}$. For the highest investigated $\mathrm{T}_{\max }$ of $500{ }^{\circ} \mathrm{C}$ the yield strength increases slightly.

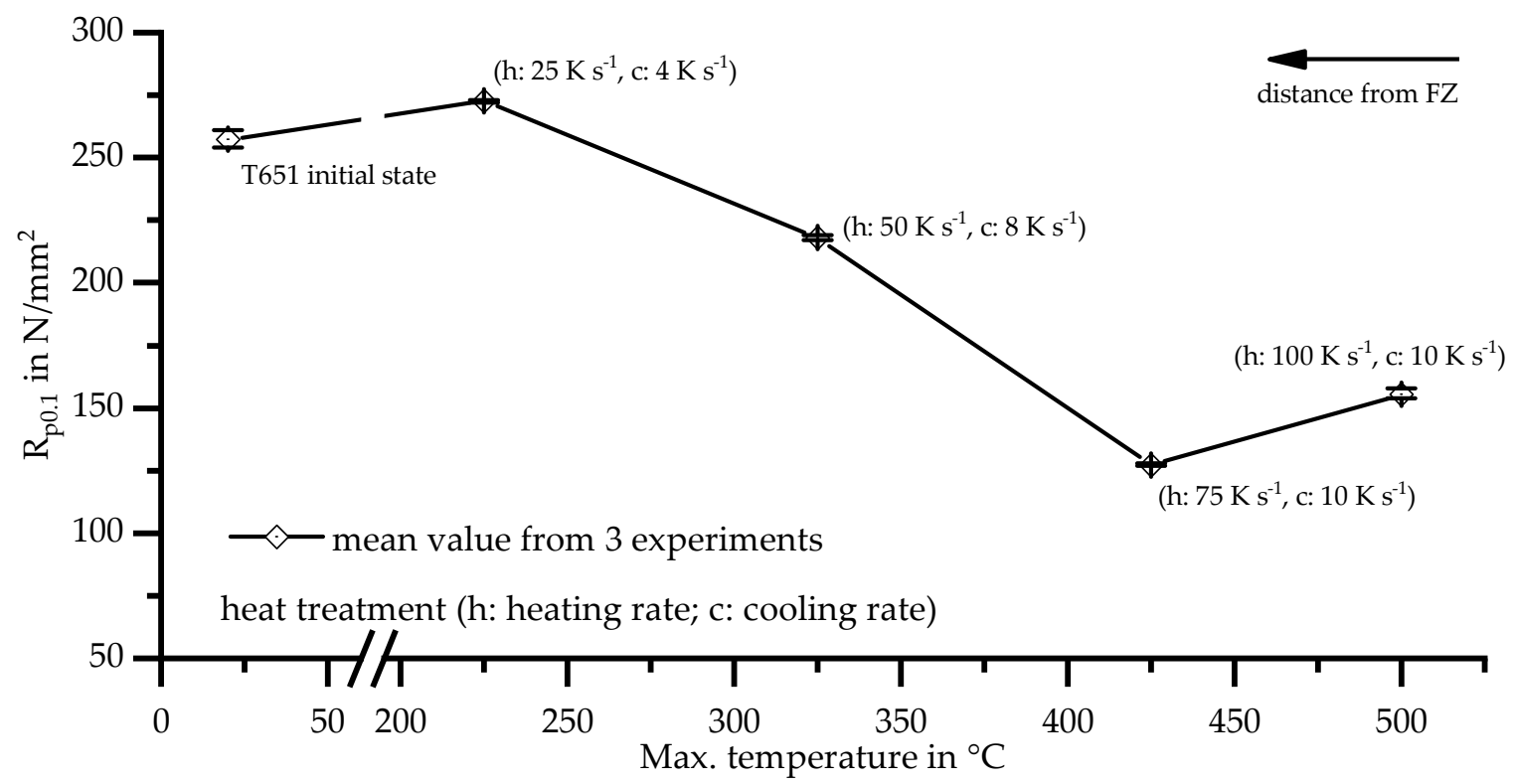

Figure 12. Yield strength after welding cycle and seven days natural aging depending on maximum temperature of short term heat treatment. 
Microstructure analyses (SEM and TEM) were performed by Fröck et al. [24] with the same material after annealing at different maximum temperatures. During annealing, both complete and incomplete dissolution of secondary phase particles was achieved depending on the maximum temperature. As Figure 9 shows, there will be an incomplete dissolution for fast heating rates. In consideration of the quasibinary phase diagram $\mathrm{Al}-\mathrm{Mg}_{2} \mathrm{Si}$ [15], the same phases are expected after the TMA welding heat treatments as after solution annealing at $540{ }^{\circ} \mathrm{C}$ [24].

Because maximum temperature correlates with distance to the $\mathrm{FZ}$, the course of the yield strength (Figure 12) depending on maximum temperature is similar to the hardness profile (Figure 11).

Regarding DSC and TMA, the HAZ of $6082 \mathrm{~T} 6$ can be divided in four areas.

A. Above $425{ }^{\circ} \mathrm{C}$, solution annealing takes place. Rapid quenching near the $\mathrm{FZ}$ causes a supersaturated solid solution with potential for age hardening. Yield strength increases again after natural aging.

B. From $275^{\circ} \mathrm{C}$ to $425^{\circ} \mathrm{C}, \beta^{\prime \prime}$ precipitates increasingly dissolve and yield strength decreases.

C. Weak precipitation of $\beta^{\prime \prime}$ happens at a temperature range of $225^{\circ} \mathrm{C}$, which leads to a slight increase in hardness and strength, but is hardly detected with DSC.

D. At a distance of more than $50 \mathrm{~mm}$ (below a certain $\mathrm{T}_{\max }$ ), the $\mathrm{T} 6$ state consisting of $\beta$ " precipitates remains nearly unchanged. Hardness is not affected.

\subsection{Flow Curves in a Welded Joint}

For the calculation of the flow curve of the base material and the fusion zone the engineering stress-strain curves determined from tensile tests on separate round specimens have been used. The mechanical properties of the fusion zone material were also determined from these tensile tests and are presented in Table 7. The chemical composition of the FZ according Table 1 appears in the range of cast aluminium alloys, which also roughly applies for its mechanical properties.

Table 7. Mechanical properties of the fusion zone material.

\begin{tabular}{ccccc}
\hline Material & $E\left(\mathrm{~N} / \mathbf{m m}^{2}\right)$ & $R_{\mathrm{m}}\left(\mathrm{N} / \mathbf{m m}^{2}\right)$ & $R_{\mathrm{p} 0.2}\left(\mathrm{~N} / \mathbf{m m}^{2}\right)$ & $A_{5}(\%)$ \\
\hline FZ & 71800 & 238 & 114 & 10 \\
\hline
\end{tabular}

Whereas the base material shows ductile failure with necking after reaching the ultimate tensile strength, the fusion zone material fails without any noticeable necking (see Figure 13a). Therefore, the combined analytical and numerical approach described in Chapter 2.6 was used to calculate the flow curve of the base material. Numerical iterations were not necessary for the fusion zone material, since no necking and therefore no multiaxial stress state was present. The flow curve of the fusion zone was simply calculated by Equations (2)-(4). An extrapolation with Equation (6) extends the curve to a larger range of strains. To validate the obtained flow curves, a comparison between calculated and measured technical stress-strain curves is also shown in Figure 13a. No differences between the measured and simulated curves are visible. 


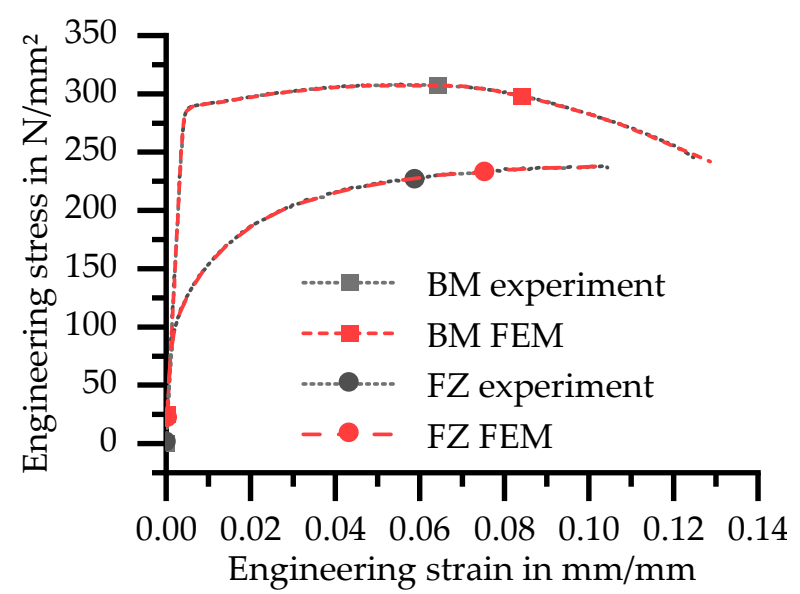

(a)

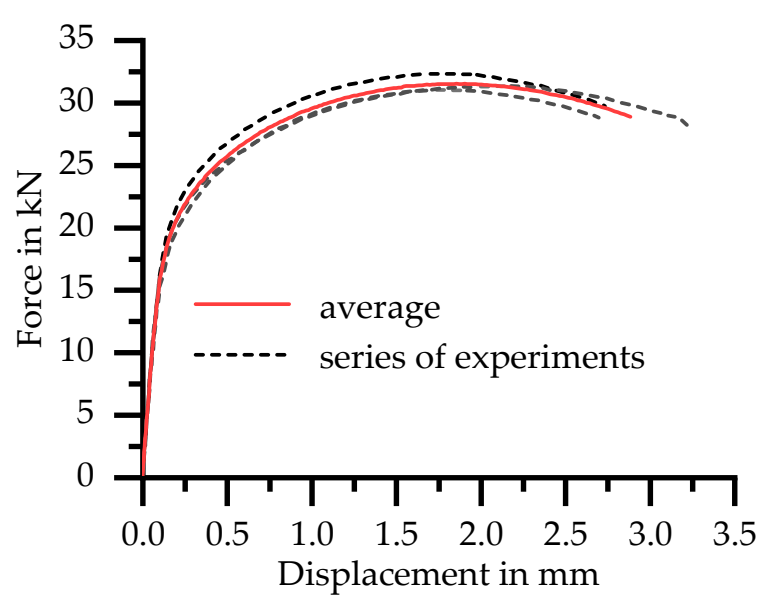

(b)

Figure 13. (a) Comparison between measured and calculated engineering stress-strain curves of base material and weld material; and (b) force-displacement curves of butt welded flat specimen.

Whereas all tests with the base and fusion zone material showed very good repeatability, the global force-displacement curves of the three tested welded flat specimens showed slight differences (see Figure 13b). It is assumed that the differences occur because of irregularities in the weld seam in length direction as well as due to specimen manufacturing from slightly different areas over the sheet thickness. To overcome the differences between curves, one average curve was used for comparison reasons with numerical simulations.

In addition to the global force-displacement curve, local force-displacement curves for the zones $\mathrm{Z} 1$ and $\mathrm{Z} 2$ were also determined by using the DIC. The respective lengths and positions of the material zones were derived from hardness measurements as shown in Figure 11. Z1 is the area between $4 \mathrm{~mm}$ and $16 \mathrm{~mm}$ distance to the centre of the fusion zone. This is the area in which fracture occurs during tensile tests. Z2 ends at $25 \mathrm{~mm}$ distance to the centre of the fusion zone when the hardness values increase to about $95 \%$ of the base material (i.e., about 95 HV1). For distances to the fusion zone larger than $25 \mathrm{~mm}$ (Z3), the properties of the unaffected base material are nearly reached.

For this arrangement, the experimental force-displacement data for Z2 only allows a calculation of the flow curve until about $0.3 \%$ plastic strain, because failure and strain localisation occurred in Z1. The curve of $Z 2$ is extended to higher strains by fitting a power law according to Equation (5). The flow curve of $\mathrm{Z1}$ is obtained afterwards through iteration with numerical simulations. In contrast to the base material, it was not possible to use Equations (2)-(4) until necking occurs (see Figure 14).

Due to the inhomogeneity of the HAZ, uniform elongation cannot be assumed until the maximum force is reached. Therefore, the experimental data were used as initial values for the numeric iteration only as long as agreement was maintained between the measured and calculated force-displacement curves. 


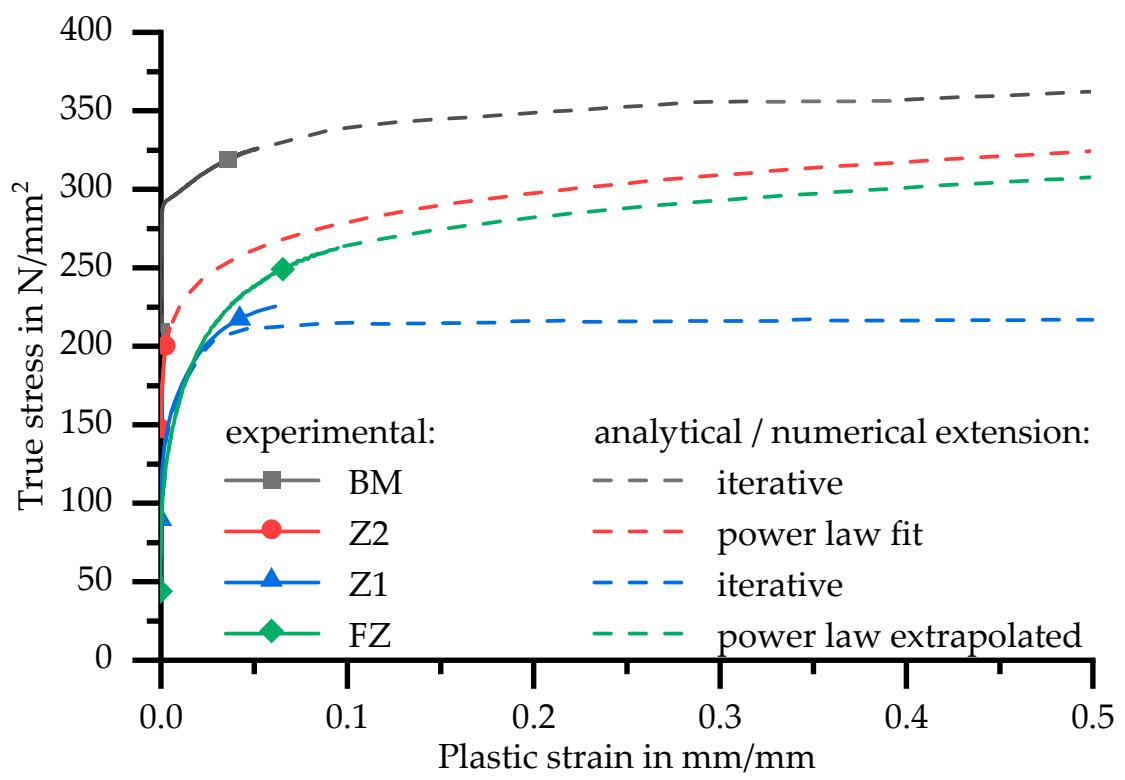

Figure 14. Flow curves of base and weld material, Z1 and Z2.

\subsection{Validation of Obtained Flow Curves in the HAZ}

The results of the tensile tests with butt welded flat specimen are here described in more detail. To validate the calculated curves, the strain distribution in the experiment (DIC) can be compared with the numerical results. Therefore, the maximum principal strain $\varepsilon_{1}$ was calculated in the DIC software at the specimen's surface. First, Figure 15 shows that no uniform elongation of the specimen is present even at low global displacements (maximum strain of $0.3 \%$ ). Whereas the hardness measurements (see Figure 11) suggest the highest strain in Z1 next to the fusion zone, the fusion zone material dominates the deformation of the specimen at low strains. The behaviour of the flow curves (Figure 14) of the two zones explains this phenomenon: at low strains, the flow stress of the fusion zone material is less than the flow stress of Z1. A certain amount of strain hardening needs to occur for Z1 to dominate the deformation behaviour of the specimen.

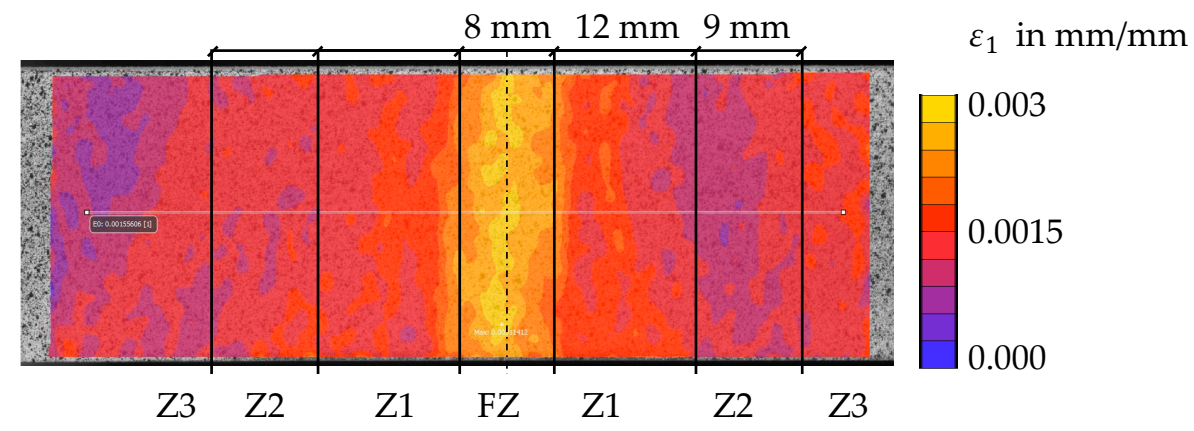

Figure 15. Strain distribution in a welded flat specimen at low global displacements $(0.1 \mathrm{~mm})$.

The top of Figure 16 shows the measured strain distribution of the specimen at $1.3 \mathrm{~mm}$ global displacement. In contrast to the strain distribution at low displacements, here, the highest strains occur almost symmetrically next to the fusion zone in Z1. For comparison, the bottom of Figure 16 shows the maximum principal strains calculated by the finite element $(\mathrm{FE})$ simulation at the same displacement. 


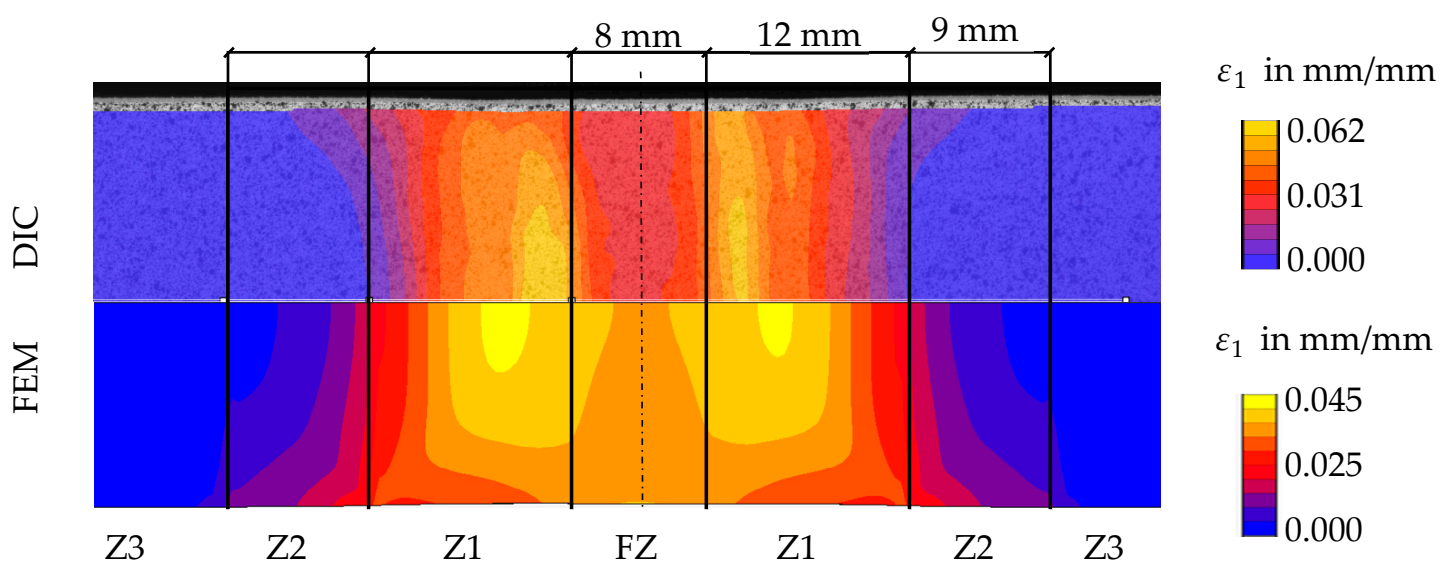

Figure 16. Comparison of the strain distribution in a butt welded flat tensile specimen at $1.3 \mathrm{~mm}$ global displacement: in the experiment (top); and in the FE simulation (bottom).

At first glance, the strain distribution shows good agreement between model and experiment. In both cases, the maximum strain is located in Z1. Whereas there are still noticeable strains in the fusion zone, the strain decreases within a few millimetres in Z2 to almost negligible strains in Z3. Since $\mathrm{Z} 3$ and $\mathrm{Z} 2$ deform less than $\mathrm{Z1}$, the deformation of $\mathrm{Z} 1$ is constrained in the width direction. This constraint causes higher strains in $\mathrm{Z} 2$ at the edge of the specimen than in the middle. The constraining effect on the different material deformations becomes stronger in the simulation than in the experiment, because the FE model has no continuous change in material properties but rather an explicit change at the end of each material zone.

Another difference becomes visible by comparing the maximum strain values. The measured maximum strain is higher than in the numerical simulation and located closer to the fusion zone. It has to be pointed out that differences in maximum strain occur even though the measured and simulated force-displacement curves of the whole specimen are almost identical (see Figure 17). This is possible because the flow curve of $\mathrm{Z1}$ averages a quite large area of the HAZ compared to high changes in hardness and the presumed mechanical properties in this zone. Since for example the lowest yield stress is averaged to a higher value, a smaller strain peak will be calculated.

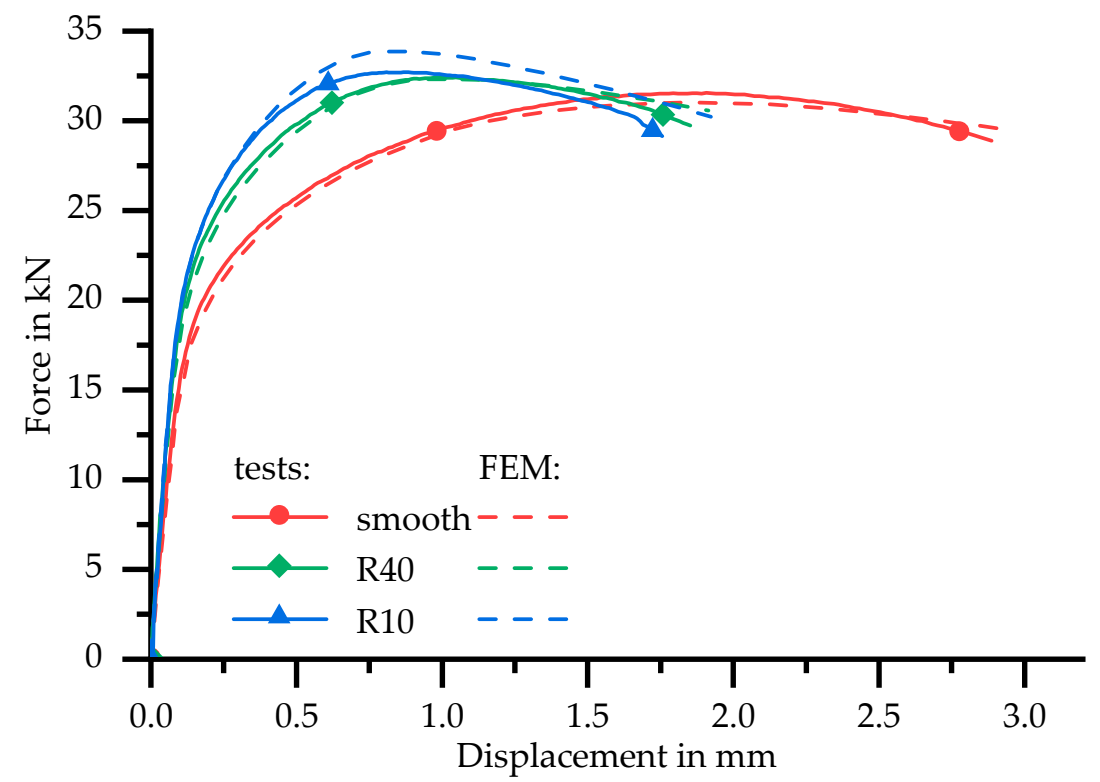

Figure 17. Force-displacement curves of notched and smooth butt welded flat specimen. 
To investigate the behaviour of the HAZ in different multiaxial stress states and to validate the obtained flow curves in more detail, tensile tests and numerical simulations of notched specimens were conducted. Figure 17 shows a comparison of three different specimen shapes: smooth, large notch radius $(40 \mathrm{~mm})$ and small notch radius $(10 \mathrm{~mm})$ with equal nominal cross sections.

As it is well known, a notch will increase the maximum force: the smaller the notch radius, the higher the maximum force. The experimental results confirm this fact. However, the increase of the maximum force is small. This indicates that the inhomogeneity of the material dominates over the geometric effect due to the notch. The increase of maximum force is calculated by the FE simulations as well. However, the simulated and measured force-displacement curves of the specimen with large notch radii have good agreement, while the simulation overestimates the maximum force of the sharp notched specimen. Due to the material properties averaged in Z1, expressed by the flow curve, a larger force is required in the finite element simulation in order to map the local strain concentration in the notch root.

\subsection{Correlation between Results of Tensile Tests and TMA of HAZ}

When comparing the results of different methods, the type of joint used for temperature measurement (T-joint) and tensile test specimen (butt joint) must be considered. Whereas in a butt weld the heat can only be dissipated in two directions, the T-joints consists of three segments. Higher $\mathrm{T}_{\max }$ as a function of distance and lower cooling rates can therefore be expected on the butt weld.

Hardness profiles (see Figure 18) of both welds were recorded in order to compare the welds and in particular the size of the HAZs with each other.

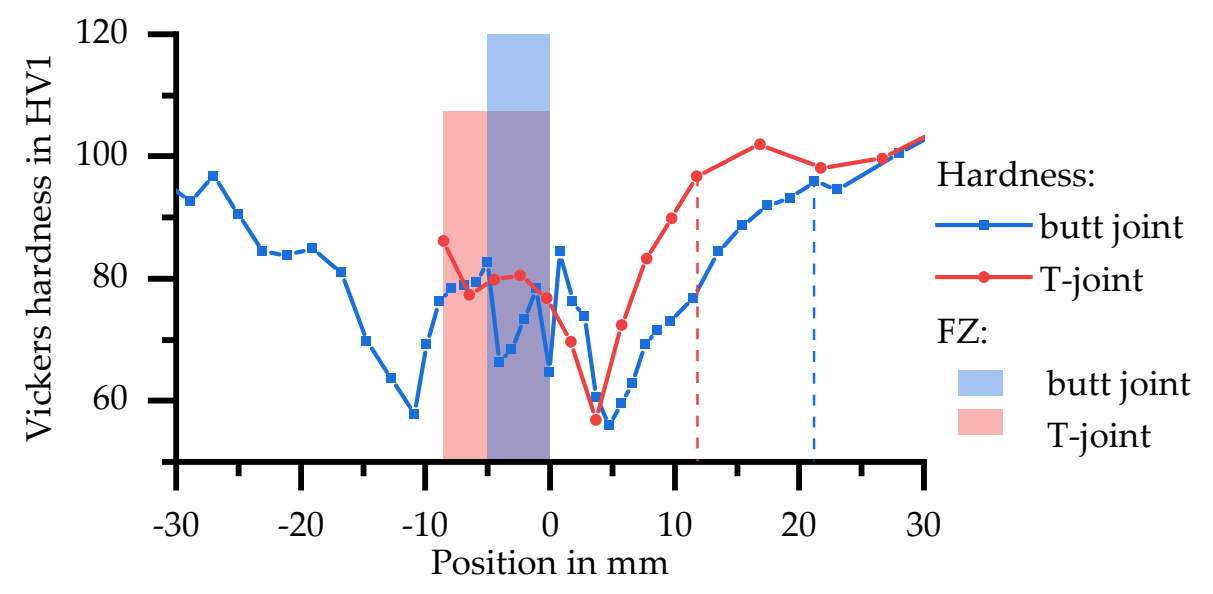

Figure 18. Hardness development in butt and T-joint depending on the position.

For the T-joint, the values of the FZ and the vertical plate are shown. In HAZ the hardness first decreases to a minimum, which is at a distance to FZ of $4 \mathrm{~mm}$ in the T-joint and at 5-6 $\mathrm{mm}$ in the butt joint. In further course the hardness increases until the initial value of about 100 HV1 is reached at $12 \mathrm{~mm}$ (T-joint) and $21 \mathrm{~mm}$ distance (butt joint) respectively. The courses of hardness are the same and the locations of, e.g., the minimum or initial hardness, match, considering the geometrically changed distribution of $\mathrm{T}_{\max }$.

Flow curves of the HAZ determined with tensile test and TMA can therefore be compared as seen in Figure 19. 


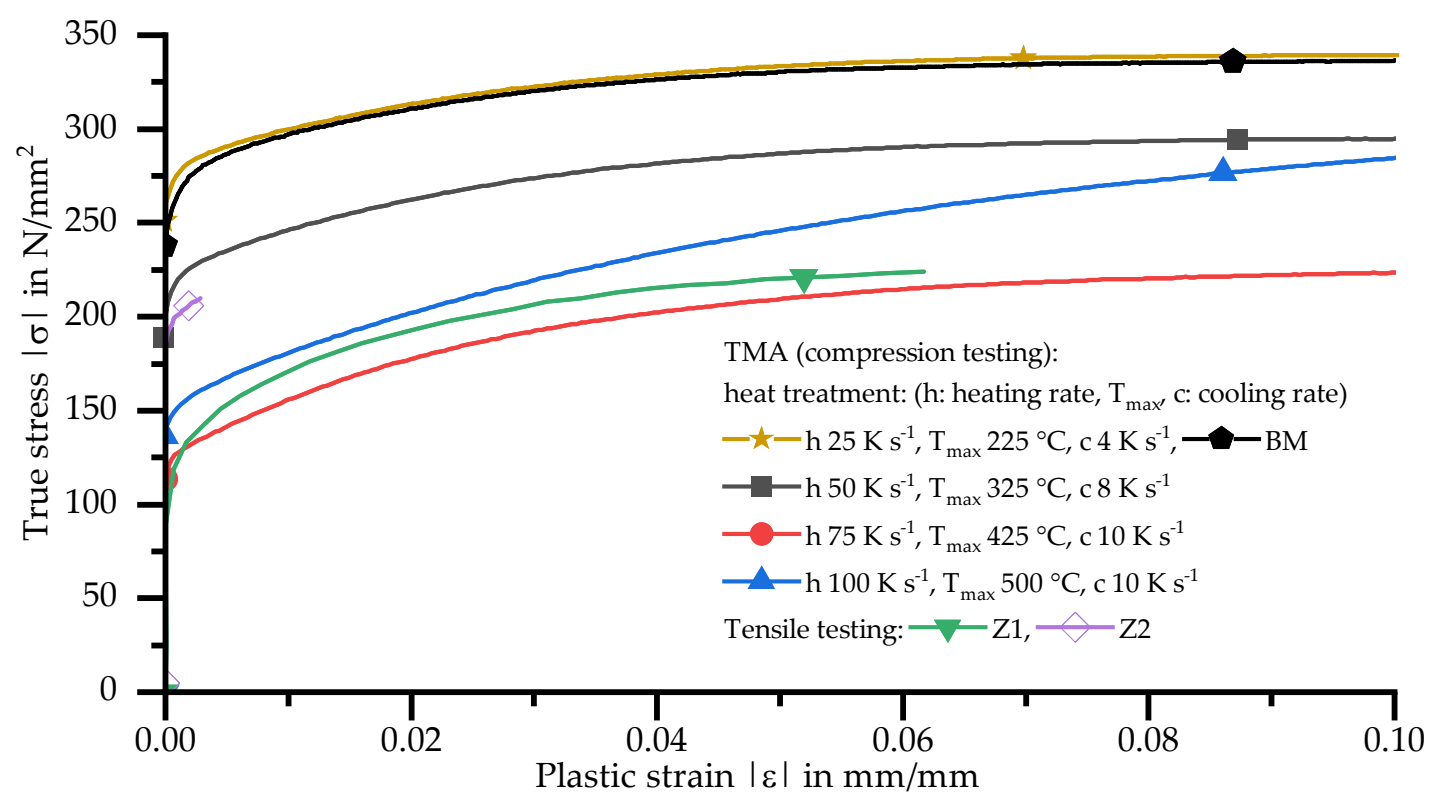

Figure 19. Flow curves of real and retraced HAZ determined with tensile and compression tests. The compression tests are carried out after the welding cycle and seven days of natural ageing.

The curve of $\mathrm{Z} 1$ is enveloped by the retraced HAZ with $\mathrm{T}_{\max } 500^{\circ} \mathrm{C}$ and $425^{\circ} \mathrm{C}$ for low plastic strains. The experimentally determined flow curve of $Z 2$ is only available up to the maximum stress of $\mathrm{Z1}$, but it can be assumed that it follows the curve with $\mathrm{T}_{\max } 325^{\circ} \mathrm{C}$. These results are in good agreement regardless of the different heat input in tensile and TMA samples. Whereas the tensile tests were carried out with specimens heated three times up to different maximum temperatures (three weld beads), the TMA specimens were subjected to a single, precisely defined short-term heat treatment.

The lowest mechanical properties are obtained by TMA with $\mathrm{T}_{\max } 425^{\circ} \mathrm{C}$. By evaluating tensile tests in $\mathrm{Z1}$ with the combined numerical and analytical approach described previously, the low mechanical properties as in the TMA cannot be determined due to the averaging in Z1. Averaging over the area of $Z 2$ leads to a curve similar to the TMA flow curve with $T_{\max } 325^{\circ} \mathrm{C}$, even though no significant difference to the $\mathrm{BM}$ is expected at the end of $\mathrm{Z} 2$. As Figure 12 shows, the short-term heat treatment with $\mathrm{T}_{\max } 225^{\circ} \mathrm{C}$ results in maximum strength just above that of the BM.

It becomes visible that a combined approach with tensile tests, DIC and numerical simulations and DSC and TMA following temperature profiles during welding can lead to an improved description of material behaviour in different areas of a weld for a specific welding process and geometry. With knowledge of the maximum temperatures depending on the distance to the FZ, phase transformations obtained by DSC and material properties obtained in a TMA can therefore deepen understanding of the microstructural changes in the HAZ and refine numerical structure-mechanical simulations of welded components.

\section{Conclusions}

In this study, HAZ properties of welded joints made of AlMgSi wrought alloy EN AW-6082 T651 were investigated using several combined methods. The following conclusions can be drawn from the consideration of the individual results and their mutual discussion:

1. Dissolution and precipitation reactions in different areas of the HAZ can be analysed in situ with DSC. To retrace the thermal history in the HAZ, the temperature rate range was extended with the indirect DSC method.

2. There is a good agreement between results of phase transformations determined with DSC and changes in mechanical properties measured with TMA. 
3. The softening in HAZ is strongly dependent on peak temperature. With increasing peak temperature, the initial state is increasingly dissolved and the material is softened to a minimum. Near the FZ, the mechanical properties increase due to strong dissolution of alloying elements and the associated potential for natural aging.

4. The development of dissolution and precipitation can be described by continuous heating dissolution diagrams, similar to welding-transformation diagrams of steels.

5. Mechanical properties from TMA and results of tensile tests on welded joints show good agreement in relevant HAZ zones.

6. Flow curves of the base material, fusion zone material and two areas in the HAZ in a butt welded joint can be calculated with a combined numerical and analytical approach. DIC measurements can provide the necessary force-displacement data in the HAZ without manufacturing separate specimens.

7. A certain amount of strain hardening in the FZ needs to occur before the HAZ dominates the deformation of welded flat specimen.

8. Small increases of maximum force with decreasing notch radii indicate that the inhomogeneity of the HAZ dominates over the geometric effect due to the notch.

9. Numerical simulations of notched tensile specimens with these flow curves lead to accurate force-displacement curves for large notch radii. The maximum principal strain is underestimated by numerical simulations, because of the averaging of material behaviour in the HAZ.

Author Contributions: All authors conceived and designed the experiments; P.W. and H.P. performed the experiments and analysed the data; and P.W., H.P. and Reich wrote the paper.

Funding: The authors acknowledge funding of this work from the German Research Foundation (DFG), within the scope of the research project "Materials Based Simulation of Limit Load Behaviour for Welded Aluminium Structures" (DFG RE3808/2-1 \& DFG SA 960/7-1).

Conflicts of Interest: The authors declare no conflict of interest.

\section{References}

1. Collette, M.D. The impact of fusion welds on the ultimate strength of aluminum structures. In Proceedings of the 10th International Symposium on Practical Design of Ships and other Floating Structures, Bowie, MD, USA; 2007; pp. 944-952.

2. Missori, S.; Sili, A. Mechanical behavior of 6082-T6 aluminium alloy welds. Metall. Sci. Technol. 2000, 18, $12-18$.

3. Mathers, G. The Welding of Aluminium and Its Alloys; CRC Press: Boca Raton, FL, USA, 2002 ; p. 34. ISBN 0-8493-1551-4.

4. Milkereit, B.; Kessler, O.; Schick, C. Precipitation and Dissolution Kinetics in Metallic Alloys with Focus on Aluminium Alloys by Calorimetry in a Wide Scanning Rate Range. In Fast Scanning Calorimetry; Schick, C., Mathot, V., Eds.; Springer International Publishing: Cham, Switzerland, 2016; Volume S, pp. 723-773. ISBN 9783319313290.

5. Fröck, H.; Graser, M.; Reich, M.; Lechner, M.; Merklein, M.; Kessler, O. Influence of short-term heat treatment on the microstructure and mechanical properties of EN AW-6060 T4 extrusion profiles: Part A. Prod. Eng. 2016, 10, 383-389. [CrossRef]

6. Graser, M.; Fröck, H.; Lechner, M.; Reich, M.; Kessler, O.; Merklein, M. Influence of short-term heat treatment on the microstructure and mechanical properties of EN AW-6060 T4 extrusion profiles-Part B. Prod. Eng. 2016, 10, 391-398. [CrossRef]

7. DIN Deutsches Institut für Normung e. V. 573-3. Aluminium und Aluminiumlegierungen-Chemische Zusammensetzung und Form von Halbzeug; DIN: Berlin, Germany, 2009.

8. Wang, T.; Hopperstad, O.S.; Larsen, P.K.; Lademo, O.-G. Evaluation of a finite element modelling approach for welded aluminium structures. Comput. Struct. 2006, 84, 2016-2032. [CrossRef]

9. Chen, Y.; Clausen, A.H.; Hopperstad, O.S.; Langseth, M. Stress-strain behaviour of aluminium alloys at a wide range of strain rates. Int. J. Solids Struct. 2009, 46, 3825-3835. [CrossRef] 
10. Törnqvist, R. Design of Crashworthy Ship Structures. Ph.D. Thesis, Department of Mechanical Engineering, Technical University of Denmark, Lyngby, Denmark, 2003.

11. Aluminium und Aluminiumlegierungen-Bänder, Bleche und Platten-Teil 2: Mechanische Eigenschafte, DIN EN. 485-2; Deutsches Institut für Normung e. V.: Berlin, Germany, 2007.

12. Ostermann, F. Anwendungstechnologie Aluminium; Springer: Berlin/Heidelberg, Germany, 2014; ISBN 9783662438060.

13. Edwards, G.A.; Stiller, K.; Dunlop, G.L.; Couper, M.J. The precipitation sequence in Al-Mg-Si alloys. Acta Mater. 1998, 46, 3893-3904. [CrossRef]

14. Dutta, I.; Allen, S.M. A calorimetric study of precipitation in commercial aluminium alloy 6061. J. Mater. Sci. Lett. 1991, 10, 323-326. [CrossRef]

15. Polmear, I.J. Light Alloys. From Traditional Alloys to Nanocrystals, 4th ed.; Elsevier Butterworth-Heinemann: Amsterdam, The Netherlands, 2006; ISBN 0750663715.

16. Milkereit, B.; Kessler, O.; Schick, C. Recording of continuous cooling precipitation diagrams of aluminium alloys. Thermochim. Acta 2009, 492, 73-78. [CrossRef]

17. Milkereit, B.; Beck, M.; Reich, M.; Kessler, O.; Schick, C. Precipitation kinetics of an aluminium alloy during Newtonian cooling simulated in a differential scanning calorimeter. Thermochim. Acta 2011, 522, 86-95. [CrossRef]

18. Milkereit, B.; Wanderka, N.; Schick, C.; Kessler, O. Continuous cooling precipitation diagrams of Al-Mg-Si alloys. Mater. Sci. Eng. A 2012, 550, 87-96. [CrossRef]

19. Milkereit, B.; Starink, M.J. Quench sensitivity of Al-Mg-Si alloys: A model for linear cooling and strengthening. Mater. Des. 2015, 76, 117-129. [CrossRef]

20. Milkereit, B.; Schick, C.; Kessler, O. Continuous Cooling Precipitation Diagrams Depending on the Composition of Aluminum-Magnesium-Silicon Alloys. In Proceedings of the 12th International Conference on Aluminium Alloys, Yokohama, Japan, September 2010; Volume S, pp. 407-412.

21. Osten, J.; Milkereit, B.; Schick, C.; Kessler, O. Dissolution and precipitation behaviour during continuous heating of Al-Mg-Si alloys in a wide range of heating rates. Materials 2015, 8, 2830-2848. [CrossRef]

22. Milkereit, B.; Osten, J.; Schick, C.; Kessler, O. Continuous Heating Dissolution Diagrams of Aluminium Alloys. In Proceedings of the 13th International Conference on Aluminum Alloys (ICAA13), 2012; Weiland, H., Rollett, A.D., Cassada, W.A., Eds.; TMS (The Minerals, Metals \& Materials Society): Pittsburgh, PA, USA, 2012; pp. 1095-1100.

23. Zohrabyan, D.; Milkereit, B.; Kessler, O.; Schick, C. Precipitation enthalpy during cooling of aluminum alloys obtained from calorimetric reheating experiments. Thermochim. Acta 2012, 529, 51-58. [CrossRef]

24. Fröck, H.; Milkereit, B.; Wiechmann, P.; Springer, A.; Sander, M.; Kessler, O.; Reich, M. Influence of Solution-Annealing Parameters on the Continuous Cooling Precipitation of Aluminum Alloy 6082. Metals 2018, 8, 265. [CrossRef]

25. Gannon, L. Mesh Dependence of True Stress-Strain Curves in Finite Element Analysis of Steel Structures; Defence R\&D Canada-Atlantic: Dartmouth, NS, Canada, 2011.

(C) 2018 by the authors. Licensee MDPI, Basel, Switzerland. This article is an open access article distributed under the terms and conditions of the Creative Commons Attribution (CC BY) license (http://creativecommons.org/licenses/by/4.0/). 